\title{
A STUDY OF PRINT AND COMPUTER BASED READING TO MEASURE AND COMPARE RATES OF COMPREHENSION AND RETENTION
}

\author{
by \\ Jackie Young, Toronto, Ontario \\ City and Guilds of London, \\ Certificate in Graphic Design, 1970 \\ Glasgow College of Printing \\ Young Master Printer's Diploma in Print Administration, 1972 \\ A thesis presented to Ryerson and York Universities \\ in partial fulfillment of the \\ requirements for the degree of \\ Master of Arts \\ in the Program of \\ Communication and Culture \\ Toronto, Ontario, Canada 2014
}

C) Jackie Young 2014 


\section{AUTHOR'S DECLARATION FOR ELECTRONIC SUBMISSION OF A THESIS}

I hereby declare that I am the sole author of this thesis. This is a true copy of the thesis, including any required final revisions, as accepted by my examiners.

I authorize Ryerson University to lend this thesis to other institutions or individuals for the purpose of scholarly research

I further authorize Ryerson University to reproduce this thesis by photocopying or by other means, in total or in part, at the request of other institutions or individuals for the purpose of scholarly research.

I understand that my thesis may be made electronically available to the public. 


\begin{abstract}
A Study of Print and Computer Based Reading to Measure and Compare Rates of Comprehension and Retention

Jackie Young

Master of Arts, Communication and Culture

Ryerson and York Universities, 2014

To the twenty-first century reader the central aspect of Gutenberg's invention of printing appears deceptively simple. Movable type, small pieces of metal cast from an alloy of lead, tin and antimony, assembled into words and lines created pages that were inked then pressed into velum to create the printed word. This was the beginning of transmitted information, the mass production and distribution of small portable books. This thesis examines the evolution of printing from the Renaissance when "fixity" was achieved to its ascension to the first mass media. The research portion of the study observes, measures and compares the interpretive strategies that readers use when engaging with the printed page and how they adapt new strategies when reading online. Print and online stories from The Guardian, The Economist and The New Yorker were coded and used in the study.

The study was conducted at Ryerson University.
\end{abstract}




\section{Table of Contents}

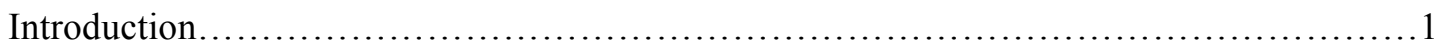

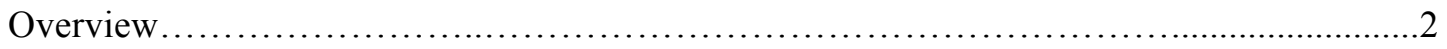

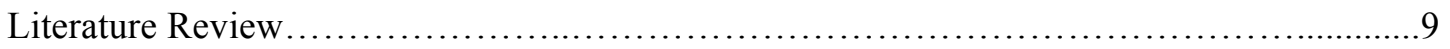

The Study's Structure .........................................................43

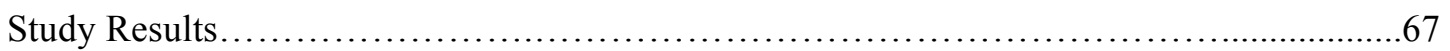

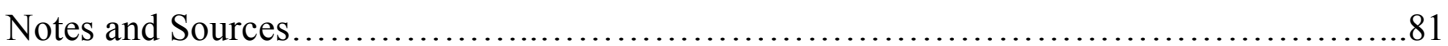




\section{Tables}

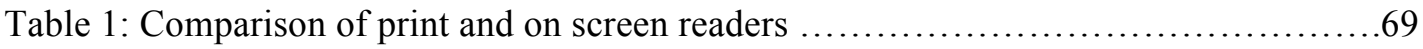

\section{Images}

Exhibit 1: The Guardian, Euro Vegas, print .......................................45

Exhibit 2: The Guardian, Euro Vegas, web ...........................................46

Exhibit 3: The Guardian, Matisse, print............................................47

Exhibit 4: The Guardian, Matisse, web..................................................48

Exhibit 5: The Economist, Yucky Kentucky, print..................................49

Exhibit 6: The Economist, Yucky, Kentucky, web..................................50

Exhibit 7: The Economist, HIV AIDS, print....................................... 51

Exhibit 8: The Economist, HIV AIDS, web........................................52

Exhibit 9: The New Yorker, Clinton, print ....................................... 53

Exhibit 10: The New Yorker, Clinton, web ….................................54

Exhibit 11: The New Yorker, Financial page, print....................................55

Exhibit 12: The New Yorker, Financial page, web ....................................56

\section{Appendices}

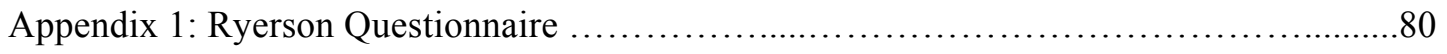




\section{Introduction}

As a society, we are now in transition from print based information gathering to an electronic screen based model. Daily newspapers shed $9 \%$ of weekly print publication sales from April 2009 to April 2010 alone (Hollander et al, 2011). My research focuses on the presentation of news in magazines and newspapers in their print and on-line versions. I have observed comparable rates of comprehension and retention of the same stories edited and presented for both media. Reader strategies for online comprehension and retention of information that differ from print will be recorded. This is the general purpose of the study. The findings will be analyzed to enhance our understanding of the cognitive processes used to retrieve and comprehend texts, which in this case will be news stories from the two media. This will aid us in studying how and why certain behavior occurs, for instance, reading in depth, scanning before committing to engaging with a story, or searching quickly for pertinent facts.

Observing and measuring the reading process can be difficult and result in inexact and confusing data (Dillon, 2008). I believe that by applying aspects of social theory it is possible to

observe, record, and measure reading comprehension and retention. Comprehension Van Dijk and Kintsch (1983) state, is a process of knowledge integration, coherence and parsing.

Comprehension will also be measured indirectly because the study research questions require the participants to understand the texts in context and retain key facts.

Lupton (2010) notes, the presentation of information through screen-based media and software on the Internet has to date, with few exceptions, been modeled on the logic and conventions of the reading process in print. By observing the reading process in print and comparing it to that of reading from a computer screen using the same news content, it will be possible to determine if a loss of information occurs. If a loss does occur and can be measured, it will allow me to formulate more precise questions that future researchers can answer. The impact of advanced information technology on the reading process is clearly an issue worthy of examination. 


\section{Overview}

Designing for print is complex but when successfully executed it gives the reader a clear and precise path to follow. It requires a skillful process of using typographic and design techniques that allow the print message to be coded, transmitted, and subsequently decoded by the receiver, the reader. As Bringhurst (2005) points out, the craft of typography shares a boundary with writing and editing on the one side and with graphic design on the other. It provides language with visual form, and through that form the meanings of a text can be clarified, disguised, or otherwise manipulated.

The continuous improvement of the printed page, typeface design, layout, typography, and understanding of eye navigation across and through printed texts has now been ported to the computer screen. Websites, E-Readers and tablets like the iPad are now emulating the reading conventions of print. The often-stated non-transferability of this intimate paper-based process to the computer screen has created a heated debate and inexact studies.

Dillon (2008) discusses the ease of manipulation and navigation that paper provides and the corresponding difficulty of doing so with electronic texts. Scrolling, measured in a study by de Brujin et al. (1992) disadvantages the reader when loss of location cues occur. Manovitch (2010) notes that despite the frequent statements that the digital revolution is at least as important as the invention of the printing press, we are largely ignorant of how the key part of this revolution, cultural software, in the form of HTML, XML coding and search engines were invented and how they function: "Not only does software and hardware participate in the reading process, it can influence how information is or is not retained $(83,84$.)" The websites of news media companies in the study will be analyzed to determine how successfully they control software in an electronic reading environment.

If we were to follow the history of the process of the transfer of information that Innis (1951) describes in The Bias of Communication, where civilizations are shaped by their use of a particular medium of communications over a lengthy period, in the course of more than five 
centuries print evolved into a mass medium. The message and its means of distribution have remained stable since the arrival of the popular mass audience press in the late $19^{\text {th }}$ century. When the print publishing and television media landscape had matured into stable and reliable sources of information, the Internet arrived. It quickly began to democratize content and lay siege to the established concepts of intellectual property and copyright. The Internet also radically changed how information was gathered, parsed, distributed, and displayed. Despite over two decades of research, there is no conclusive understanding of how humans interact with, and process information from, screen based media content from the Internet (Dillon, 2008). Recent studies have continued to observe and measure aspects of online reading against print but no definitive answers have emerged.

Lupton (2010) and Manovich (2012) place a significant emphasis on the role of software in determining what is being presented to the online reader and how. But most of the studies that I have researched do not adequately address this pervasive aspect of the online reading process. Neuman, Just and Crigler (1992) documented how news is specifically framed for television and print media, but there is little evidence in research to date that indicates a similar approach to online media and the use of computer systems and technology to influence the selection and presentation of news content.

The study will observe and record comparative cognitive processes in both print and electronic media and seek to explain the differences, if any, in the readers' information gathering processes and their subsequent comprehension and retention of information. It is a small research project that examines a single phenomenon, the way in which readers gather information. The study may develop into a relationship or comparison of ideas and generate questions that future researchers can investigate, such as the influence of technology on the reading process.

\section{The invention of printing and the book}

There is currently an acrimonious academic debate on the subject of "print culture," and when the stabilization of printed information in the form of the book occurred. Hesse (1996) states that the 
stabilization of written culture into a canon of authored texts, the author as creator, the book as property, and the reader as an elective public were not the inevitable consequences of the invention of printing during the Renaissance but the cumulative result of social and political choices made by given societies at a particular point in history. She cautions that the term "print culture" implies a technological determinism that fuses the means of cultural production, the printing press with the historical development of a mode of cultural production, "the civilization of the book (21)."

Eisenstein (1979) argues that the emergence of printing in the fifteenth-century gave recognition to the author, the originator of texts, which in turn created the concept of intellectual property, copyright, the protection of the author's texts, and the concept of plagiarism. The printing revolution of the Renaissance, which made knowledge both more accessible to a new reading public and made the book a trustworthy and stable source of information. She concludes that the author's words were perceived as the truth, which equates to stable, and with that print culture achieved "fixity."

Johns (1998) disagrees and in an examination of scientific publishing in seventeenth-century London concludes that the recognition of printed books as accurate and reliable depended on prior approval of the Stationers community who oversaw and policed the publishing industry in England. These prior representations created order and civility and "fixity depended on civility." To Johns, truth, consensus and agreement result from socio-cultural negotiations that are conducted at the local level. By the end of the nineteenth-century he states "print and fixity were as firmly conjoined by culture as ever could have been achieved by machinery (632)." The process that achieved this he states was the arrival of steam printing, which had superseded the craft of hand printing in replicating the printed word.

This discussion on "fixity" has implications for aspects of my research study findings. The transfer of text from print to the Internet has technological implications that Hesse (1996) discusses. The author as creator, books (text) as property, and reader as elective public become 
fluid and potentially unstable in an electronic environment. Knowledge she concludes, is no longer contained in space but passes through it like a series of vectors, "each having direction and duration yet without precise location or limit (31)." The idea of "fixity" to Eisenstein happened very rapidly during the Renaissance, within fifty years of the invention of printing. Johns states that the technology of print was unstable and did not mature until the eighteenth-century when mechanical reproduction ensured exact replication. This question, the discussion of the emergence of print "fixity" requires clarification. If the Internet is at present fluid and unstable, is this merely part of its evolution? Or, when the printed word is transferred to the Internet, does the new medium permanently alter the message? As Keep (2005) observes, hypertext poses a unique set of challenges. The book is read more or less in the same common manner while hypertext reading has no shared experience as it takes shape only in the act of reading. He concludes that the emphasis shifts from the text and its themes and patterns, and on the way it comes into being through "an ensemble of cultural and technological competencies (5)." And he poses the question, what are the cultural mediations/adaptations that this requires?

The development of the book was dependent on two major events, the adoption of parchment in place of papyrus and the replacement of the scroll with the codex. The codex was developed by the Roman Empire as a portable writing surface. Two hinged tablets of wax or slate could record notes that later were transcribed onto papyrus. Compared to the scroll which was cumbersome and fragile, the codex was less easily damaged, allowed for writing on both sides, and could be easily stored by stacking on shelves. It also had the flexibility to be separated into smaller parts and reassembled into a collection or library. While the scroll permits only consecutive reading the codex allows for more interactive information retrieval. A codex provides more than a narrative, it provides a research resource (Pettegree 2010).

Early Christian texts used sheets of papyrus stitched together to allow for a more flexible codex based recording and reading process. With the arrival of parchment that could be written on both sides, religious texts when embellished by decorative calligraphy and bound created the 
first book. The book as we know it evolved from this process and has remained both popular and resilient. When Gutenberg produced his first edition of the bible he followed closely the then current book model, the illuminated manuscript. He designed and cast type in the style of the black letterforms of calligraphy and used colour initial letters to mimic the illuminated manuscript's decorative illustrations. His bible was enduring and influential and subsequent publications of the bible followed his design. Virtually all of these early editions also used Gutenberg's choice of text, a copy of the Latin Vulgate. As Pettegree notes, "Unwittingly, therefore, Gutenberg (and print) played a major role in the fixing of the text of the Vulgate as the standard authorized text of scripture (30).”

The spread of print with the use of parchment and the black letterform led to the early acceptance of printed books in established European publishing markets that had traditionally sold illuminated books. The early experiments with colour were replaced with a typographic approach to breaking up the text with large initial capitals, sub-headlines, and illustrative woodcuts. This process of replacing decoration with a typographic hierarchy was the beginning of the process of providing order for the reader. Printers slowly moved to the production of black and white books. In the last quarter of the fifteenth-century printing spread throughout the German Empire both in university cities and centres of commerce. As Pettegree notes, these merchant communities with their experience funding large capital investments were crucial in the development of the German publishing industry. A new breed of entrepreneur emerged, the merchant publisher, who could command the vast amounts of capital required to fund large book projects that needed skill, time and a sophisticated network of sales agents to ensure success.

Printing also flourished in France with the influx of German immigrants. As their skills developed, new markets were sought. Paris publishers who had served the church found that print was a natural progression from the production of manuscripts. However the initial success of European publishing with its large capital requirements and long production and sales cycles, both of which required a stable fiscal and political environment, went through long periods of 
adjustments. The Nuremberg Chronicle, a massive publishing venture financed by two wealthy Nuremberg merchants was printed and distributed by the publisher Koberge. It took two years to manufacture and was completed in 1493. A further five years were required to complete the distribution and sales cycle, Pettegree notes. A financial crisis and flight of capital from Venice eradicated its once vibrant industry. In Italy, a glut of books in Florence arrested the advance of print in that city. Until printers and publishers learned to gauge what type of content the new reading public wanted, this process would continue. Wars, a succession of plagues, and other destabilizing events also contributed to the slowing of the advance of print.

It was possible to avoid these pitfalls. The Renaissance Venetian printer Nicholas Jenson partnered with two Frankfort merchants and their capital investment allowed Jenson to publish for new markets in law, medicine, and theology. Jenson's roman typeface, a departure from the black-letter gothic typefaces, gave his books a distinct and in terms of the advancement of design, sophisticated look. His typeface designs are still in use today. Another Venetian publisher, Aldus Manutius, a Greek scholar, also successfully employed typographic innovation. His publication of classic Greek texts in italic texts in small portable octavo formats required a considerable investment in design and technology. Aldus employed the type designer Francesco Griffo to create a typeface based on his handwriting. The result was a compact highly legible and efficient italic roman typeface. So the first roman typeface was actually italic. Other less reputable Italian printers copied his design, reprinted his texts and attempted to replicate his typefaces to profit from Aldus's publishing success. While he could not sue his competitors for publishing texts that were in the public domain, Aldus applied for a twenty-five year patent for his unique type design, which he was granted (Pettegree 2010).

Sher (2006) in an examination of the Scottish Enlightenment notes that the complexities of eighteenth century publishing were overcome through a remarkable collaboration between publishers in Edinburgh and London. Despite working in an intensely competitive commercial framework, publishers in Scotland and London joined forces to share costs to market and 
co-publish authors. Sher concludes that Johns' focus on London during The Enlightenment and narrow scope of examining the structures and relationships that characterized the publication of scientific books cannot successfully study the relationship between print and knowledge. He notes that Johns' contention that piracy and plagiarism occupied readers' minds just as prominently as fixity and enlightenment may be true of scientific publishing in seventeenth-century London. "It is not necessarily true of books in philosophy, law or fiction from that same time and place. Limiting his analysis to scientific books prevents Johns from establishing the universal significance of his model for book history (10)."

The output of European publishing from 1450 to 1600 and its financial requirements would suggest that it was a mature industry, certainly in Germany, which enjoyed a relatively stable political and fiscal system of government. Pettegree notes that the first press established in Oxford in 1483 had failed within two years and the attempt to start a press at Cambridge University in 1520 was equally short lived. Books for the Universities in Latin were exclusively handled from the continent via London. Johns' focus on the English scientific publishing world and his reluctance to include continental Europe in his research has in my opinion severely restricted his findings. Plagiarism existed in seventeenth-century Europe and the hand setting of metal type was error prone. Plagiarism is still with us and despite the electronic environment we live in with spell checking, research databases and other Internet resources books still contain errors and inaccuracies. Gutenberg's choice of text, a copy of the Latin Vulgate Pettegree notes, unwittingly created "fixity" of that text for the scriptures. That occurred in 1452 and of the initial print run of approximately 180 copies fifty still exist today. "This was a book that from the beginning was cherished and treated with awe (29)." 


\section{Literature review}

This literature review will look at the philosophy of technology, how we communicate through reading, specifically the influence of computers, tablets, and e-Readers and their presentation of text. How news is structured and framed for the different media and an examination of on-line reading that previous studies have conducted and measured is also included.

\section{The philosophy of technology}

McLuhan (1964) states that when a message passes through a new medium, the medium alters the message. He concludes, "The message of any medium or technology is the change of scale or pace or pattern that it introduces into human affairs. Therefore, the medium is the message itself

(8).” Hansen (2006) elaborates:

To begin interrogating (this) oscillation with which contemporary media challenges theory, the oscillation between materiality and phenomenology, let us return to one important if partial source of (Kittler's) media history, namely Marshall McLuhan's formalist conception of mediation, the medium and the message...to effect a conceptual shift from the content of a message to its technical form, such that the content simply became the technical form (298).

It is this transformative power that is, for McLuhan, the real message of technology. Gane (2005) notes that McLuhan, critical of the theory of Shannon and Weaver (1949), drops the information source, the sender, and the final destination of communication. He focuses instead on the channel, the medium, and the changes they cause. Gane elaborates; "The basics of all contemporary Western theories of communication, the Shannon Weaver model, is a characteristic example of left-hemisphere linear bias. It ignores the surrounding environment as a kind of pipeline model of a hardware container for software content. It stresses the idea of inside and outside and assumes that communication is a literal matching rather than making (27)." Heim (1997) notes that both 
McLuhan and Heidegger understood the connections between new technologies and the way the mind processes information. Heidegger's inherent information anxiety and McLuhan's understanding of the television medium confirmed their vision of the role of technology in framing how content is presented by a new medium. In McLuhan's terms its environment is always invisible and its content is the old technology: "As a consequence the old technology is considerably altered by the action of the new technology (544)." Heim examines Heidegger's assertion that the danger of technology is that it enters the inmost recesses of human existence, transforming the way we know and think and will. He states that: "Technology is, in essence, a mode of human existence and we could not appreciate its mental infiltration until the computer became a major cultural phenomenon (542)." Heim concludes that this drive for technological mastery is pushing into the human interior where thought and reality meet in language. Heidegger (1957) on the pervasiveness of the computer states;

The language machine is, and above all is still becoming one way in which modern technology controls the mode of the world of language as such... Meanwhile the impression is that man is still the master of the language machine. But the truth of the matter might well be that the language machine takes language into its management and thus masters the existence of the human being (i).

Heim notes that McLuhan (1964) helps us understand what the computer does specifically as a language machine, as a component of human knowledge. McLuhan supports Heidegger's treatment of language as a transformative aspect of being: "An enthusiasm for Heidegger's excellent linguistics could easily stem from naïve immersion in the metaphysical organism of our electronic milieu...there is nothing good or bad about print but the unconsciousness of the effect of any force is a disaster, especially a force that we have made ourselves (554)." Heim states that to McLuhan, Heidegger's ideas have a greater appeal to a culture organized electronically because such a culture has already left behind the detached, linear, individualistic mentality of 
literate or print cultures. Heim concludes: "McLuhan agrees with Heidegger in asserting that language technology belongs to us more essentially than any other tool. When a technology touches our language, it touches us where we live (544)."

\section{Communication through reading}

A text is a message, and the study of communications concerns messages, their senders and receivers and the relationship among the three. It is a process of exchange and transaction where a message is encoded by the sender, received and decoded by the receiver. In this way people engage in interpersonal communication. There are two other kinds of communication, intrapersonal, talking to oneself and human/machine and machine/machine communication. As Hatt (1976) has noted, anybody examining communication expecting to learn about people talking to each other is likely to have to penetrate a terminology and a set of concepts, which come from telegraphy and computer technology. These can take the form of signals, noise, feedback, redundancy and entropy. Hatt describes interpersonal communications in the following terms: "A selects signs from a vocabulary to encode a message, which is transmitted to B, who decodes the signs to receive the message (102)."

This triad includes:

\section{Transmitter.}

2. Message.

\section{Receiver.}

If we were to incorporate this model into a reading process, one that makes the reader the subject, it can be expresses as the following:

1. A reader finds a text.

2. She reads the text, and decodes it.

3. She accepts the message, or not, as the case may be Hatt concludes. 
From this the question becomes what kind of reading operations does the receiver perform on the text and what does she take from the text? Or: Who is the reader? What does the reader want? What is the text? How do reader and text come together? What is the nature of the reading? What ensues from the reading?

It is necessary to examine these questions carefully to fully understand the act of reading. Reading in alphabetical languages is conventional not iconic in that the visual patterns that form the word house does not resemble the appearance of a house. Words are a visual stimulus unlike radio or speech, which are both auditory. The printed word is derived from writing and as such constitutes language transfer. As McLuhan (1964) observes, the content of writing is speech, the written word is the content of print and print is the content of electronic media. If asked what the content of speech is, McLuhan concludes that it is necessary to say that it is: "The actual process of thought, which in itself is non verbal (24).” The printed word, unlike conversation, does not allow feedback or clarification. It is also time and space binding in that it can bring together reader and author, even though they may be centuries apart.

Hatt states: "There comes a time in a reader's development when the recoding and decoding processes become simultaneous, so that the reader decodes directly from what she sees on the printed page, its graphic input. This enables her to read much more quickly, taking in large areas of type, editing out redundant letters, words and phrases. In fact reading is a rapid series of guesses, tentative information processing (98).”

\section{Reader response theory and interpretive strategies}

Nord (2001) examines reader response to urban newspapers in the early twentieth-century. He drew on readers' correspondence with a Chicago newspaper editor to explore the reading strategies that they, the readers used to make sense of what was read. He notes that reader response was not always idiosyncratic but was linked to reading conventions that are identified as a form of interpretive communities. In the case of Chicago he states, organized political groups 
sometimes influenced these conventions and communities. Balance to the readership consisted of fairness and impartiality which they perceived as the cornerstones of modern journalism.

However, these active readers simply wanted more of it based on their point of view. Nord notes that at the individual level readers appear diverse, idiosyncratic and free. If we were to observe at a higher level of abstraction, readers become more comparable, predictable and constrained. "This apparent change in human nature is produced not by a change in reality and philosophy but by a change in methodology, a change in perspective (276)." It is therefore possible to view readers as both active and passive, creative and constrained. He concludes that distinct patterns emerged from an analysis of the content of the reader letters. The content of newspaper stories cued the readers to link one story to another in an attempt to impose a meaningful order in the mass of information they encountered. Similar to the modern reader these letter writers, “...necessarily brought to the task of reading a repertoire of interpretive strategies of response (269)." This in turn shed light on their concept of what a newspaper should be, which required an understanding of the methodology and conventions of journalism in an era of rapid change. Reader strategies were politically influenced not only by personal beliefs but also through organized political interest groups. Nord concludes that the letters to The Herald and its editor Keeley reveal an active community of readers, but one that was "....actively rooted in the social and political institutions of time and place (269).”

Bishop (2005) notes that the key feature of book history is its connection to materiality and history. Abstract ideas on what constitutes a text do not consider that meaning is always produced in a historical setting. Meaning, he concludes depends on "the different readings assigned to it by historical rather than ideal readers (1)." Reader response is therefore the interpretive activities of readers who move beyond the author's original intention. Goldstein (2005) states that readers synthesize perspectives from a text's content but the text still guides and directs them. But it is the reader who through experience creates a coherent interpretation. 
For the modern reader, interpretive strategies are still required when confronting the continuous barrage of news. As print is replaced by electronic delivery of information, the reader must learn new ways to navigate the conventions of the Web. To make sense of the news and its authenticity as best they can.

\section{The reading process}

Van Dijk and Kintsch (1983) state that there is no unitary process 'comprehension' that could be measured once and for all if we could but find the right test. Comprehension, they postulate, is a common sense term that dissolves upon closer analysis into many different sub-processes: "Thus we need to construct separate measurement instruments for macro-processing, knowledge integration, coherence and parsing. Comprehension is just a convenient term for the aggregation of these processes. It is not to be reified, not to be tested for (364)." As all of the researchers above have noted, reading is a process of decoding and analyzing coded transmitted messages. Only when the reader has completed this complex series of decoding tasks by scanning for clues while editing out redundancy, matching the message against accumulated knowledge to construct meaning, can this tentative information processing be comprehended by the mind as a message. The research question "is the on-line reading process similar to reading the printed page as measured by the reader's comprehension and retention of information?" will require a close examination of a reader's processing of the printed word, which has been extensively researched. A second question, "What reading strategies that differ from print, do readers adopt when reading on-line?" will also be examined. Research into the on-line reading experience has been unsystematic and as Dillon (2008) has noted, research on reading electronic text is piecemeal and of little direct use to designers and editors working in an electronic publishing environment.

Marchionini (2010) states that for over a century, the process of reading has been the subject of continued examination by scientists from a variety of disciplines. However, for all of that effort, the process has still to be adequately described. "Psychology has formed our understanding 
of the cognitive activities, while information science has concentrated on the more pragmatic issues of providing people with access to stored material through search engines, and associated information architecture (1.1)." He further states that the impact of advanced information technology on the reading process is clearly an issue worthy of examination, with the impetus provided by electronic text in general and the Web in particular:

Outcomes such as comprehension, are considered to the extent that they are influenced by the reader's ability to use the text... until we have sufficient knowledge about the relationship between information presentation and subsequent learning or comprehension then the efforts of electronic text designers concerned with usability should be concentrated on providing the tools to access and manipulate relevant material in a suitable manner (1.3).

He concludes that media itself is plural and cannot be considered a determining factor in learning outcomes. The attainment of comprehension or other outcomes are probably contingent on access provided by well-designed intermediary systems.

Despite over two decades of research there is no clear understanding of how humans interact with, and process information from screen-based media content from the Internet (Dillon 2008). This has raised questions about the effectiveness of the Internet as a medium for reading and absorbing information as the navigation and conventions of clicking and scrolling are foreign to the print reader (Bolter 2003). Dillon has concluded that current research on reading electronic text is both piecemeal and of little direct use to those responsible for designing these tools, primarily as a result of the uni-disciplinary definitions of reading adopted by researchers, the limited tasks examined and the resultant failure of any descriptive framework or model to provide a means of conceptualizing the range of issues involved when people read a document.

As both Dillon and Bolter point out, the cognitive processes required to navigate, process, and comprehend text on screen differ substantially from those required for reading in print, which is a 
linear process that has a familiar navigational flow. Bolter has observed that the computer screen creates a series of visual configurations that the reader encounters through the reading process. The electronic hypertext, unlike print, which is static, has both the reader's eye and the writing surface, the electronic screen, in motion. Computer text and graphics, Bolter notes, can be animate in the sense of having their own organic impulse, of appearing to move or change according to their own logic and in their own time. For example, when the cursor passes over an image or a hypertext link, it changes its appearance and prompts the reader for a response.

Responding to a cue to access a footnote may be the print equivalent, but it does not interfere with or complicate the reading process. Dillon describes onscreen reading as complex. It demands an attention to text and images that differs from the print experience. Readers shuffle between two modes of reading - they learn to read in a way that combines verbal and picture reading. This requires the activating of signs by typing and moving the cursor to check spelling and correct throughout and then making symbolic sense of the motions that their movements produce. Dillon describes paper as: “An information carrier par excellence and possesses an intimacy of interaction that can never be obtained in a medium that by definition imposes a microchip interface between the reader and the text (3-02)."

It is important to understand that old media practices like reading and navigating through print, which is tactile, do not readily transfer to an electronic environment. As McLuhan (1964) observed: "The objectives of new media have tended, fatally, to be set in terms of the parameters and frames of the older media (23)."

\section{The influence of software}

In the creation of the printed page software is a passive tool, it does not directly influence the structure and design of the page. As Bringhust (2005) states below it is under the control of the originator. When content shifts to the digital it can as Manovich (2012) observes, be freed up and appropriated to create new forms of content. For example Adobe Photoshop, originally used as a 
production tool to balance and prepare colour photographs for the printing press, is now a creative software tool. This has permanently compromised the authenticity of the photograph. Not only are digital photographs manipulated, re-coloured, and re-edited from their original context, but digitization requires every photograph to be passed through software, primarily Photoshop, which permanently alters the image. Databases originally conceived as storage devices are now the gatekeepers and conduit for this fluid digital content.

Lupton (2010) states that: "Web sites are controlled by hierarchies in an even more systematic way than print documents. A site's file structure proceeds from a root down to dictionaries holding various levels of content (99).” The presentation of information through screen based media and software on the Internet has to date, with few exceptions, been modeled on the logic and conventions of the reading process in print. This however has had unforeseen consequences. A joint Stanford/Poynter (2008) eye-track study recorded how readers engage, navigate and read online newspapers. This study contradicts conventional publishing theory and practice, that when the design conventions of print are transferred to the Internet, the reader responds to the computer screen as they would the printed page. The Stanford/Poynter study research suggests this is not the case. The online reader for instance, ignores the visual print design cues, photographs and display headlines and seeks the first text item at the top left of the screen regardless of visual stimulation. While the reading conventions of a book or texts with no art content conform to the focus of top left when turning the page, in the design of magazines and newspapers the photograph is used to arrest the reader as she travels through the pages. The photograph is also used as a navigational cue when the reader moves back through a magazine to re-engage with a story. The online reading strategy bypasses these visual print conventions. In examining information processing, Martin (2011) concludes:

Our brains are contextual retrieval architectures, but computers retrieve based on indexes, pointers, probabilities, etc. The two architectures each have their strengths but also weaknesses. 
Manovich (2012) in comparing cinema, the printed word and the human computer interface, each of whose traditions has developed its own unique method of presenting information states that these are the three main reservoirs of metaphors and strategies for organizing information which feed cultural interfaces. The human computer interface has a cultural language that differs from both print and cinema and offers its own ways to represent human memory and experience: "This language speaks in the form of discrete objects organized in hierarchies, or as catalogues (databases), or as objects linked together through hyperlinks (hypermedia)." The digitizing of media has freed it from its traditional linear storage confines and the digital designer can freely mix content: "No longer embedded within particular texts and films, these organizational strategies are now free floating in our culture, available for use in new contexts (82-83).

Not only does software participate in the electronic reading process, it can influence how information is or is not retained. This is not the case with print, which has an established set of reading conventions that have been in place for over five centuries. As Bringhurst (2005) observes, the software processes employed in the creation of the printed page are under the control of the creator despite the increase in technical capacity of the software: "I have still been obliged at times to subvert the software forcing it to do things that its makers did not foresee, or things they foresee and expressly excluded (365).” Online, HTML software controls the text and how it is displayed which strips out important typographic conventions that are critical to reading and retaining the printed word.

\section{Observing and measuring the online reading process}

Eye-tracking technology has been used by researchers to observe and record how a reader engages with a print document, a newspaper, book or magazine or website. In this way, eye movement studies show that readers collect information only during the span of a fixation, which is the point where word recognition takes place. The information gathered is used to 
identify the length of upcoming words and to identify the best location for the next fixation point, allowing for the measurement of two reading operations, how the reader seeks out information by navigating the document or screen and the time it takes to retrieve it.

Using eye-tracking technology, Nielson and Pernice (2010) conducted a study on the interaction between readers and newspaper and consumer websites. When the eye is resting on a screen element it is termed a fixation. The eye's rapid movements from one fixation to others on the screen are termed saccades. The researchers observed that when this rapid movement that lasts between one-hundredth to one-tenth of a second occurs, the optical image of the retina blurs so much that the reader is effectively blind during a saccade. The reader does not actually see what the eye is moving across. They see and record only during fixations, while the eye is holding still, they concluded. Nielson and Pernice employed slow motion replays to document their observations and built heat maps as a visualizing technique for eye-track studies. They created gaze plots to show a user's visit to a webpage plotting each fixation. The larger the dot, the longer the fixation, and the lines between the dots represented saccades. This implies that the way readers look at any given artifact, such as a webpage, is determined by what they are trying to do with it. The task the user has chosen or has been asked to do, determines their actions.

Other studies on the subject of the effects of the computer screen on the cognitive processes of reading decoding and comprehending text messages have measured reader response to print, computer screen and tablet fixations. Zambarbieri and Carniglia (2012) conducted a study that analyzed the comparative eye movements during silent reading of the printed book, a computer screen, an iPad tablet and a Kindle eReader. Using a video camera and eye-tracking devices the authors measured fixations, where the eye observes information and the mind records it and regressions, where the eye returns to previously read text to re-examine it.

The results focused on two aspects of reading behavior, the mean duration of fixations and regressions and percentage of regressions with respect to the number of progressive fixations. As the authors note, since vision is suppressed during saccade execution, it is only during fixations 
that the central nervous system can elaborate visual information. "Thus fixation duration is a well established indicator of the difficulty of perceptual and/or cognitive processing in reading (394)." Zambarbieri and Carniglia found that there were significant fixation differences between the PC and the iPad and the PC and the Kindle eReader. When measured, the reading process on the PC was longer than the other devices. However mean fixations for the iPad, and Kindle were no different than those of the printed book. This is consistent with my study's research although in my case the PC and tablet measured equally.

\section{The content, structure and framing of news}

As Nord states above, readers bring to the task of reading a repertoire of interpretive strategies of response which in turn sheds light on their concept of what a newspaper should be, in particular, its content. Grabber (1998) in examining cognitive processing concludes that schematic information techniques, gathering and assessing information are critical in parsing the vast amounts of text that the reader is confronted with. How news is written, structured and presented in one medium might not be appropriate for another. For example the inverted pyramid style of newspaper writing that pushes the salient points of a story to the first few paragraphs was adopted to allow editors to fit the news into the page by editing out less important information from the end of the story. Neuman, Just and Crigler (1992) note that the compact, simplified requirements of television broadcasting allow for early framing of topics in a news story.

The online reading experience where space is unlimited and content fluid has resulted in reader confusion and apprehension. This was a constant theme in my study focus group discussions. Authors whose texts in print are secure now face the prospect of their words being destabilized because of the fluid nature of the Internet. Because the conventions are still in flux, Heim (1997) states that making text flexible gives additional written commentary and responses to texts the same credibility as the author's. The study group participants noted that this created uncertainty and fostered a distrust of the accuracy of most website content. 
In measuring the processing of news from multiple sources, Grabber (1988) identifies three elements that require investigation. The first is the actual brain functions involved in processing information. The second is the body of accumulated information that provides the respondents with raw materials for information integration. The third essential feature in research design is a suitable theory. Preliminary hypothesis testing she notes, points to schema theory, as the most appropriate approach.

The most important element in any research design, Grabber states, is the theoretical perspectives from which the data are collected and processed. Schemata, she concludes; determine what information will be noticed, processed and stored so that it becomes available for retrieval from memory; help individuals organize and evaluate new information so that it can be fitted into their established perceptions and this makes it unnecessary to construct new concepts whenever unfamiliar information is presented; make it possible for people to go beyond the immediate information presented to them and fill in missing information, which permits them to make sense of incomplete information. Schemata also help people solve problems because they contain information about likely scenarios and ways to cope with them. This makes an important element in deciding whether to act and how to act.

Cognitive processing Grabber states: "Does follow patterns that are best explained in terms of schemata theory. In the realm of news, readers must cope with the flood tide of information through a manageable, limited array of schemata that are simple and sparse in basic dimensions as well as with the number of themes included in the dimensions (245).” A cognitive map, she concludes, is a specific way of representing a person's assertions about some limited domain, such as a policy problem. It is designed to capture the structure of the person's causal assertions and to generate the consequences that follow from this structure.

The traditional news media have specific ways of shaping the news for their medium that organize and simplify the flow of information to the consumer. In other words they make it manageable. Neuman, Just and Crigler (1992) carefully monitored the news over a three-year 
period and used detailed, extensive interviews to measure the 47 participants' sense of the content and its presentation and knowledge gained. The media were The Boston Globe, Time, Newsweek, U.S. News and World Report, CBS Evening News and ABC World News Tonight. They found that television's tendency to frame the early aspects of a story, appeals to the viewers' emotions and simplifies complex concepts. News magazines frame less, but provide an understanding of problems outlined in the early stage of a story. Newspapers, with their inverted pyramid writing, emphasize facts early, according to importance. This, the researchers concluded, tends to make them feel too complex for some audiences.

Audiences for print and television, for instance, have different and distinct expectations for each medium and how it shapes the news. The researchers' findings contradicted the media's own understanding of their role in writing for print and television. International politics and technically complex debates around complex missile defense systems were more successfully communicated through television with newspapers doing least well and magazines falling in between. Local news content on AIDS and drugs, human-interest stories thought more suitable for television fared better in print. Perceived media bias that television over-simplified news was dispelled, although the research showed that people with poor cognitive skills relied more on television news. Those with high cognitive skills were very motivated and scored higher with all three media and learned as a group, the most from television as well as print. It was noted that television with its reinforcing visuals and animated graphics gave the audiences contextual information that print did not (131-132).

When information moves to a new medium, from print to television or from television to the computer, the user interface also changes. Watters, Sheppard, Chaisson and Manchester (2004) investigated two designs for electronic news presentation. One was a document based window text only display, while the other, a broadsheet newspaper presentation, allowed the viewer to skim through the content of headlines and photographs and select news stories. This screen-based design relied on newspaper print conventions for presentation for both photographic and headline 
display. The goal of the study was to achieve reader satisfaction in "reading the news", whether that was in an electronic newspaper environment or a shallow hierarchy of pick and read text window presentations. Research conducted at Dalhousie University explored these two distinctly different metaphors for presenting electronic news. Walters, Sheppard, Chaisson and Manchester noted that this did not allow for a true random sample, but rather a sample where students, academics and university support staff were participants.

The research results showed an overwhelming preference for the newspaper metaphor. This was consistent across all age and education levels. Walters, Sheppard, Chaisson and Manchester concluded that the subjects in the study were in favour of a broadsheet presentation of the electronic news.

Marshall (2004) reported in a field study conducted on behalf of The New York Times, on an RSS-driven, template-based reader. The Times News Reader (TNR) was a hybrid application that tested newspaper readers and their adaptability to different types of on-line reading. Subscribers to the newspaper were asked to evaluate the TNR experience in a journal. The data gathered measured the newspaper like qualities of the TNR to understand if this hybrid was sufficiently "paper like" to draw readers away from the print version. The TNR, an application, was synchronized to download and be as timely as the delivery of the print version. It was updated periodically throughout the day.

As Marshall noted, the advantage of the TNR was that it presented an electronic book version of the newspaper. It was a paperless newspaper designed for on-screen reading. Navigation employed both tactile print simulations of page turning and movement and drop down menu conventions of the Internet. Marshall recorded the skimming and scanning reading practices and concluded that a modified presentation of news content while maintaining reading in depth functionality was needed.

The research from this field study, which included both participant, and researcher journals, interviews and focus groups, found that the loyal readers were still unwilling to part with the print 
based newspaper. Readers also preferred the Times website's constant streaming of breaking news, something they could check on if a particular news story interested them. Marshall concluded that the TNR was both less flexible than the printed and not as timely as the website. My study participants in focus group interviews concluded that Internet content always requires confirmation from other sources as to its accuracy unless it is a trusted publication. For researching facts print is the preferred source, for confirming Internet news it is mainstream broadcast media websites like the $\mathrm{BBC}, \mathrm{CBC}$ and $\mathrm{CNN}$.

McLuhan (1964) developed the concept of a new medium, television, displacing and eventually making obsolete the old medium, print. Nosssek and Adoni (2001) set up a study to test this hypothesis in Israel, a western society with a large reading public which is also inundated with a multi-channel news media environment. They used empirical data collected in different points in time between 1970 and 2001. The data was collected by several studies using telephone and face-to-face interviews. The sampling was across all levels of Israeli society. A model was created based on three theoretical approaches that described the possible interactions between the media. The interaction between any two media, print and television, arises from their varying functional equivalence. Where functional equivalence exists they hypothesized, one medium might make the other obsolete. What the Nosssek and Adoni research revealed was that there was a pattern of co-existence and interchangeability between media and that culturally and socially, print had a significant and persistent presence. This was measured and confirmed across all age groups and genders.

Nearly all of the research sample groups regularly viewed television and listened to the radio. Nosssek and Adoni concluded that books and newspapers connect people with similar interests and revealed a strong interest in sharing and discussing information. The displacement of print by television and the Internet they state;

Is inapplicable in the dynamic relationships in a multi-channel media environment... The new technologies, the PC and Internet will not lead to the disappearance of print media. 
The unique functions of reading in fulfilling psycho-social needs and consequently the low functional interchangeability or reading with other media may explain the persistence of book reading as a cultural behavior and the scale of the reading public in Western democracies (107-108).

This study, conducted over a period of thirty-one years, examined the impact on the supremacy of print with the emergence of electronic mass media in the form of television. Nosssek and Adoni also observed the later introduction of the personal computer and the Internet, which together impacted an already complex multi-faceted media environment. The tenacity of the printed word in an era of instant communications would suggest that it has built an enduring trust with its readership. The study group confirmed this phenomenon of trust of the printed word and its perceived accuracy. They state that they always go to a print source to check the accuracy of Web content.

Marshall (2010) in a qualitative study observed and interviewed committed magazine readers to compare print to e-Book readers. This study was designed to test the hypothesis that committed print readers could be convinced to migrate to e-Books. Close observation via videotaping sessions where the individuals normally read was also used to detect detailed reading patterns. Marshall noted that books and magazines have simple and intuitive navigational aids. The cover art and use of cover lines introduce the content. The contents page sets up the navigation, and with page numbers, allows the reader to flip through a work quickly for orientation. In this way she concluded, print offers a reader clues about where he or she is. Although it tries to replicate the print experience the e-Book has no capacity to fulfill these simple navigational functions. In contrast to the Internet experience where the medium is used to expand on or alter traditional reading patterns, the e-Book attempts unsuccessfully to convert a computer into a printed book. The study group stated that they found e-Readers awkward, with bright screens that did not respond to different reading and lighting conditions. 
Marshall points out that skipping an article by turning its pages quickly has a different overall effect than skipping to the next article using a link. Close observation of the three readers with videotapes revealed some other general patterns: the overwhelming majority of navigation acts were forward page turns; when people read print publications, they used a variety of lightweight navigational techniques to manage their attention. Marshall observed that readers rely on the serendipitous encounter to expose them to material they might otherwise skip if they relied on metadata, such as titles and authors alone. My study participants used words like "skim" and "glance" to describe how they read electronic texts. In general they characterized on-screen reading this way to contrast it with how they read print materials, which they described as more in-depth. The study group also described the online experience as "skimming," not reading, a place to search for information then leave. While they also initially skimmed print they returned to read in depth. Print readers read closer than when online; there is more interaction with the page, especially the newspaper, one study participant stated.

Marshall concludes that until the computer screen has the tactile look and feel of paper the media will exist as two solitudes.

Corio (2011) conducted a study predicting reading comprehension on the Internet to test and measure information about teacher directed on-line reading for students. The study was framed around a model of four literacy components, locating, evaluating, synthesizing, and communicating. The study, however, took a narrow view of synthesis and communication. Corio notes that the study synthesis was limited to a reader's ability to compare, contrast, and integrate information across three particular web pages with paragraphs of similar factual print on the same topic. Students were not asked, for instance, to synthesize information across multiple media formats or across online locations that presented distinctly different perspectives on one or more topics. So the study had a very narrow focus. Similarly, students were asked to communicate their answers using an online quiz interface The patterns emerging from this study only hint at the complexity likely to be found in future studies that examine how 
readers negotiate broader conceptions of all the dimensions of a new literacy perspective. One of the findings from this study suggests that print reading comprehension can inform, but not complete, our understanding of online reading comprehension.

Corio concluded that in essence therefore, these findings might serve to cautiously validate the notion that reading skills and strategies beyond those measured by traditional reading assessments are required to read proficiently on the Internet: "As we seek to more precisely define the new literacies of online reading comprehension, consideration should be given to how best to build on and expand traditional conceptions of print reading comprehension in ways that help us truly appreciate the complexities of those aspects of Internet reading that appear to be uniquely new and different (367-372)." In my study, the participants stated that they relied on print reading skills to scan websites for relevant information. This linear process of information gathering has been adapted by them to cope with the challenges of online reading. Growing up with print then transferring to a hybrid of online and print reading and research is for someone in their midtwenties, possible. But the group was concerned that those younger readers who "did not grow up with print that we did," would not develop the print reading skills they had and would therefore be disadvantaged.

Connell, Bayliss, Farmer (2012) studied the effects of e-Book Readers and tablet computers on reading comprehension in an academic setting. The research question asked whether text presentation on computer tablets affected reading comprehension when compared to the same texts in printed form. iPad and Kindle readers were the devices used in the study and the researchers noted that the iPad's note-taking feature increased its functionality for academic reading.

The study's findings were that the text presentation on the electronic devices did not affect reading comprehension but that those reading from the tablets read slightly but significantly more slowly than those reading print. Reading time was affected by the device but longer reading times were not reflected in participant perceptions of task difficulty or device usability. The researchers 
noted that despite these encouraging results, there could be some reluctance among students to adopt e-Book readers and tablets for academic reading. These devices require more time to use than the paper medium. Connell, Bayliss, Farmer noted that this is consistent with earlier qualitative studies in which participants indicated that they found the e-Book reader more appropriate for fiction that is meant to be read linearly rather than non-fiction (academic texts) which may require the reader to repeatedly seek specific information in the text.

Coiro (2003) examined the skills and abilities needed to interact with text on the Internet by exploring the answers to four questions: Is the comprehension process different on the Internet? If so, what new thought processes are required beyond those needed to comprehend conventional print? Are these processes extensions of traditional comprehension skills, or do Web-based learning environments demand fundamentally different skills? And if comprehension is different on the Internet, what implications do these differences have for comprehension instruction, assessment and professional development? Corio notes that: "If new literacies are necessary to navigate the hyperlinks skillfully in ways that enhance comprehension, a reader must understand the advantages and disadvantages associated with having ultimate control of the direction in which text progresses and use inferential reasoning skills and context clues to discern one type of hyperlink from another (463).”

Corio states that in addition to the hypertext and hypermedia features, Web-based text environments are, by their very nature, interactive. Readers are invited to co-author online texts as they navigate various paths and construct a personal adaptation of the information. Conventional texts, she notes, present information shaped by the author, and readers have little choice but to follow the author's intended plot or expository structure; they cannot interject, search the text instantly, or re-author. Readers can choose to flip through the pages of a conventional text in a different order; however most are designed to be read in a linear fashion, and (with the exception of annotation), their features are not malleable. 
New comprehension processes are therefore required for these electronic text environments. Corio elaborates: "With traditional texts, pre-reading thought processes focus on questions such as the following: What will happen next? What do I know about this topic? What is the author's purpose? What do I expect to learn from this text? Within interactive Web-based environments, however, proficient readers also need to plan answers to questions like these: How should I navigate this information? How can I expect to interact with this environment? What is my role or task in this activity? How can I add to this body of knowledge? (463)"

Corio concludes that electronic tools demand new literacies such as manipulating electronic databases, using multiple search engines, and navigating hierarchical subject guides. Like new media literacy skills, new search techniques are vital skills for us to teach as we strive to develop proficient readers in the future.

As is discussed below, it was the interaction between the reader and the interactive Web environments that frustrated the study group. Returning to a print source where the author's information is "fixed" and where the conventions and interpretive strategies are well established and its presentation carefully organized inspired trust. "Books are crafted but online is ubiquitous, online is anarchy and everyone is free to publish," stated one participant. They see the Web as fluid, difficult to navigate and interact with. Scrolling through long unstable texts that may have been re-authored, or be deleted in the future is not an activity they enjoy. Unless the information comes from a recognized trusted source it is discounted. So the question of engaging with the Web to the study group is dependent on the quality of the information and its source.

The RAND Reading Study Group, (2002) states that: “The consequences of reading are also considered part of the reading activity and can include the knowledge that a reader has gained, the applications that a reader makes, and the level of engagement that a reader maintains while involved with a text. Web-based learning environments can foster opportunities for more diverse knowledge gains, more personal applications, and higher levels of engagement (19-20).” 
The RAND Reading Study Group in discussing the direction that reading research in comprehension is likely to take over the next two decades also recognize that: "We live in a society that is experiencing an explosion of alternative texts...electronic texts that incorporate hyperlinks and hypermedia introduce some complications in defining comprehension because they require skills and abilities beyond those required for the comprehension of conventional, linear print (xv)."

The RAND Reading Study Group defined reading comprehension as the process of simultaneously extracting and constructing meaning through interaction and involvement with written language. They proposed a developmental heuristic of reading comprehension that includes three elements: The reader who is doing the comprehending, the text that is to be comprehended and the activity in which comprehension is embedded. They conclude that these three elements occur within the socio-cultural context of the reader's classroom, home, and neighborhood, and they help a reader to interpret information and create personal meaning; it's fundamentally a cultural process. Processing text involves, beyond decoding, a higher-level linguistic and semantic processing and monitoring. This would include skimming, to get the gist of text and studying reading texts with the intent of retaining the information for a period of time.

d'Haenens, Jankowski and Heuvelman (2004), in a study of news in on-line and print newspapers and the differences in reader consumption and retention posed the following questions: A; Is reading behavior different when reading the print version of a newspaper as compared to reading the online version of the same newspaper. And B; Are readers of the print version of a newspaper able to recall more news events than readers of the online version of the same newspaper.

Two Dutch newspapers were selected for this study: the national newspaper de Telegraaf, and the regional newspaper de Gelderlander. Both newspapers have online versions with comparatively the same amount of news as their respective print versions. In terms of internal validity, two groups of students were randomly assigned to either the print or on-line version. 
Both experimental groups were treated identically, except for exposure to the print or online newspaper version. Students were recruited from two universities in the Netherlands to participate in the experiment.

There is evidence that reader behavior is different when reading a print or online newspaper version the researchers noted. The extent to which stories are read - completely, partially, by title only, varied for both newspapers in the print and on-line versions (380-381).

Looking at the findings as a whole however, no consistent pattern is evident regarding how readers respond to the respective online and print versions. Similarly, recall of news differed between the two newspapers and between the on-line and print versions, but these differences fail to suggest a clear pattern in ability to recall news.

It appears that the manner in which readers consume and recall news by online and print newspapers is more complex and varied than is reflected by this study, d'Haenens, Jankowski and Heuvelman conclude. The researchers note that despite numerous investigations, to date, evidence has not been found supporting tendencies suggested in studies by Tewksbury and Althaus, (2000) that online readers may consume and retain news differently from the readers of print versions of the newspapers. Whether this result is a product of the limitations of their experiment, or whether it is a general apprehension regarding the arrival of on-line newspapers remains unclear, they state. d'Haenens, Jankowski and Heuvelman conclude that these findings support the call for continued systematic research on the subject of on-line news services, and particularly of the way in which readers of traditional print newspapers adapt their habits to an Internet-delivered news environment. The researchers did not indicate whether the online versions of the newspapers had the same typographic hierarchy as the print nor did they discuss the layout of the print and online editions, both of which would affect outcomes. This was an aspect of my study where the print and online versions of stories having exactly the same content typographic hierarchy, gave an accurate measurement of retention. Their questionnaire gathering processes were administered two weeks after the final readings, which would affect 
retention outcomes.

Tewksbury and Althaus, (2000) note that the way news sources on the Web use visuals, graphics and inter-connectivity techniques may encourage readers to process on-line stories differently from how they process traditional newspaper articles. Also: "The lessening of editorial control over story presentation and hierarchy, a function that print editors exercise over story prominence and placement means that on-line services have tended to provide far less direction to their readers regarding what deserves attention. As a consequence on-line newspaper providers may provide a readership that is more poorly informed than readers of traditional newspapers about the core events that shape public life (463)."

Tewksbury and Althaus state that the cues print newspapers typically give readers regarding a story's importance are both reduced and re-organized when the paper goes on-line. "Article lengths and headline size cues are eliminated or muted in most on-line newspapers...only when they (the reader) click on the story do the additional cues become visible (465).” They further state: "Not only may story selection differ between these groups (on-line and print), it may be one group, (print) is more cognitively engaged with the news and recall more details about the stories they have read (465-466)."

Tewksbury and Althaus, (2000) in subsequent research on print and on-line versions of The New York Times noted that print readers had a better recall of events than the readers exposed to the on-line version who: "Were less likely to recall details about public affairs (472-473)."

In my study, the participants were more engaged with the print versions of the publications, in particular, the newspaper where the full-page view gave them a sense of the complete reading process. Online reading with its narrow horizontal window that required scrolling down to read was frustrating. It did not however affect reading outcomes. As Tewksbury and Althaus state above, the print design cues critical to the reader's understanding of the importance of a news story are reduced and reorganized in the online newspaper. This they conclude affects recall outcomes. The publications in my study retained the typography and story hierarchy of their print 
editions online. Recall outcomes were exactly the same in both.

As both Bolter (2003) and Dillon (2008) have emphasized not only do the cognitive processes required to read online differ from print but also the attempts by researchers to observe and measure this phenomenon have mostly failed. The limited tasks measured and the lack of consistency in the framework employed have rendered the data collected flawed and of little use

for future research. More recent studies by Connell, Bayliss, Farmer (2012) and Zambarbieri and Carniglia (2012) have however made headway in this area. Their findings are similar to mine in that the PC, e-Book readers and tablets did not adversely affect the reading process.

Review

Lupton (2010) and Manovich (2012) place a significant emphasis on the role of software in determining what is being presented to the reader and how. But most of the studies that I have researched do not address this pervasive aspect of the online reading process. As Martin (2011) observes the human mind uses contextual retrieval processes but the computer in response retrieves information from databases based on pointers and probabilities. It makes calculated guesses as to what information we need. Neuman, Just and Crigler (1992) documented how news is specifically framed by writers and editors for television and print media, but there is little evidence in research to date that indicates a similar approach to online media and the use of database technology to correctly influence selection and presentation of content. Manovich (2012) states that when content is digitized it is free to be repurposed. Digitization of analogue content creates new media, new content that is coded and added to databases for online distribution. This would validate McLuhan's (1964) hypothesis that the content of new media is the old medium.

Heim (1997) notes that to McLuhan, a culture that is organized electronically has shed the linear, individual mentality of print culture. McLuhan also agrees with Heidegger's (1957) assertion that when a technology touches our language it has a profound influence on society. 
However, shedding print protocols and embracing electronic communications can have unforeseen consequences. The linear print mentality of reading, as the study participants noted is a central coping strategy in retrieving information online. The Internet is having a profound influence on society that to the study participants is a negative one. The fixity of print and its relatively stable linear structure is being replaced by the fluidity of electronic text, which is difficult to navigate, unstable, and unreliable.

Marchionini (2010) states that the issues around advanced technology require an examination of information processing and comprehension, which would provide greater understanding of how electronic texts should be designed for reading if conducted without the influence of the media and its software that carries the message. Dillon (2008) promotes paper as the perfect information carrier because the cultural protocols around print reading have been well established and criticizes the flawed inexact, electronic reading process. He points to numerous studies on the reading process that provide no guide to solving this dilemma; these studies fixate on small details of reading and fail to advance knowledge. Marchionini and Dillon agree that reading can be observed, and it has been for over a hundred years. But academic research on measuring reading to date has often been of little use when approaching the design of electronic texts. However, eye-track technology has been successfully used in research to observe and track reader response to the presentation of online texts.

Stanford/Poynter (2008) in an eye-track study concluded that the design conventions of print did not necessarily transfer to the new medium of the Web. Nielson and Pernice (2010) used eyetrack technology to track saccadic eye movements in studying how people navigate websites. The technology was also used by Zambarbieri and Carniglia (2012) in their study that analyzed the comparative eye movements for printed books, computer screens, tablets, and eReaders. They measured fixations and regressions to assess the time taken to read print and the electronic devices. Nielson and Pernice (2010) have with eye-track technology, documented how readers engage with websites as they search for information. Their findings are similar to 
Stanford/Poynter, the readers employ selective attention by editing out and disregarding nonessential information or visual cues. Only what is considered as essential information is retained.

Current research has indicated that when tracking eye movements in both print and online it is possible to observe and predict how a reader engages with a page and begins the process of extracting relevant information. Zambarbieri and Carniglia's study points to the measurement of fixations, saccades and regressions as perhaps a way of measuring reading on various devices using scientific methods. It cannot however determine how the mind selects, stores and processes information.

Corio's (2011) study of junior grade students' online reading concluded that print reading comprehension can aid but not complete the understanding of online reading comprehension. Skills beyond these of print reading will be required for reading proficiency on the Internet. In an earlier study on the new skills that the Internet reading process of online hypertexts needs, Corio (2003) states that online reading requires new forms of literacy. The linear processes of print are not malleable, they are fixed, where the flexible electronic texts inside a Web based environment require new navigational skills, new search techniques, and new protocols. The RAND (2002) study also points to the need for processing and decoding techniques beyond the current linear skills that provide us with comprehension of printed texts.

In examining print comprehension and retention, Grabber (1988) examines a reader's cognitive processing in terms of schemata, which determines what information is processed and stored to be available to be retrieved from memory. Hatt (1976) concludes that a reader's simultaneous decoding allows her to read more quickly, editing out redundancy, turning reading into a process of a rapid series of guesses, which allows for tentative information processing.

Studies have investigated ways of transferring the tactile familiar reading process of print to the Web. Watters, Sheppard, Chaisson and Manchester (2004) measured reader response to two presentations of news, one a shallow window text only display and a second a broadsheet that relied on the print conventions of a hierarchal typographic structure. The second presentation was 
overwhelmingly preferred which confirms that readers need guidance in helping them set priorities when engaging with electronic content.

In her field study, Marshall (2004) tested a template-based reader, an electronic newspaper version of The New York Times. Efforts were made to emulate the print experience with page turning and movements similar to print that encouraged scanning. The test group did not find the device particularly useful, preferring the newspaper's print edition for reading and The New York Times website for breaking news. When asked what prompted them to check a story online, my study group said they responded to Twitter and Facebook prompts from friends. They then checked the news online before confirming its accuracy with what they considered a more reliable source, a major news agency. In a second study, Marshall (2010) observed reader interaction in print and online. The readers skimmed and glanced at the online content in contrast to the more engaging and in-depth print reading experience. In a similar way my study group said that they read print more carefully while skimming through electronic texts to extract relevant information. They do not appear to engage with the author through the text online as they do in print. Nossek and Adoni (2001) have concluded that despite the emergence of an electronic mass media, the endurance of print is based on well-established protocols that resonated with its readers.

The d'Haenens, Jankowski and Heuvelman (2004) study attempted to measure the differences, if any between online and print presentations of two newspapers. While the print and online reading in both newspapers varied, the researchers were unable to detect a clear pattern. The consumption and retention of news was more complex than the research methods employed to measure the process was their conclusion. However, Tewksbury and Althaus (2000) did confirm that print readers had better recall than online readers of the same stories. But it was the transfer to the online editions, which stripped out the editorial typographic nuances that prioritized the content that was the issue.

My study group found the default HTML coding of online texts to be bland and when 
reformatted it created a form of typographic mayhem. Scrolling through a dense mass of electronic text is tedious and discourages reading online. The Internet they conclude is no place to digest information or absorb long articles. They are impatient when they encounter long online material. One paragraph is all they would commit to read. It would appear that the visual typographic cues developed over five centuries that guide the reading process are too important to be lost, to be stripped out and replaced by hypertext and hot links. It has also been assumed that the Web and its ability to publish endless amounts of text, enriches the reading process by providing additional background information. My study results suggest otherwise; less information is considered more than sufficient.

Newspaper writing has to be concise; it has to compress complex information into a finite amount of space. Magazines, especially newsmagazines, while they have more available writing space, require the same discipline. Broadcasting and television in particular has mastered the news sound bite. As Neuman, Just and Crigler (1992) have observed, television simplifies and presents complex information in a way that allows any audience to understand. The creators of print media measured in my study understand their readerships and write accordingly. They are also aware of the fact that readers expect content to be carefully organized, that the presentation has been thought through in advance. As one of my participants remarked, while holding up The Guardian newspaper, someone (an editor) has made the correct decision - it is more "official," and the words are of a "higher quality."

\section{The question of "fixity."}

Over the span of five hundred years the printed page has achieved familiarity, it is trusted, authoritative and its content is considered accurate. After reviewing the writings of Eisenstein (1979), Johns (1998), Sher (2006), Hesse (1996) and Pettegree (2010), I have concluded that printing in the form of a sustainable publishing environment with a solid financial business model, copyright protection and the conventions governing reading was in place in the major 
centres of learning and commerce throughout continental Europe by the late sixteenth century. Print had achieved "fixity." The sheer scale of the financial commitment and time required to make and sell books served as a deterrent to those who might try to find ways to profit quickly from the new technology. Many tried but the failure rate was very high.

My research will focus on the editorial design and print reading processes in which I am particularly well versed. I have redesigned 13 daily newspapers in North America and I have introduced design structures that allow the modern print reader to quickly access and absorb information on the page. This is also a feature of my magazine work. In my teaching at OCAD University I explore the range of possibilities in the transfer of this knowledge to emerging technologies on the Internet, eReaders and hand held devices.

\section{Design and the online reading process}

Pettegree (2010) observes that when Gutenberg created the first printed book his inspiration was the illuminated manuscript. He used the technology of the future to replicate what had existed since the introduction of the codex. The book did not emerge as a fully formed, compact and portable information source until Aldus used the existing technology to create the first roman typeface. This allowed large amounts of information to be efficiently stored in a small space, a precursor to the electronic storage devices we use today. The migration of texts from the printed page to the Web has followed a similar pattern. Editors and designers, well versed in the conventions of print communication, have transferred those protocols to the reading process online.

With the design of the online newspaper, the banner advertisement dominates the top of the page. This is followed by the newspaper's title-piece, its brand. News elements are clustered below, sometimes orderly, sometimes not, in an attempt to generate interest "above the fold," the area at the top of the newspaper that in the era of the broadsheet, was the reader's first view of the news. In online design this view is what is displayed before the reader scrolls down through the 
content. As is the case in newspapers, a photograph that is part of the lead story is the largest editorial element, the focal point of the news. When as in print, a lead news photograph is unavailable or not considered visually appealing, a stand-alone photograph that directs the reader to an inside story, one that does not merit a page one placement, is used. Unlike the modern newspaper that restricts the placement of advertising on page one to a page top or bottom banner, the online presentation of news is accompanied by a cluster of small advertisements that cling like limpet mines to the text.

This is the environment that the modern online reader is presented with. As Bolter (2003) observes, computer text and graphics move or change according to their own logic and time; hypertext and photographs change their appearance when the cursor moves over them, prompting readers for a response. This begins a navigation through the news or to other resources within the newspaper's databases or to other external sources. The study participants found scrolling down through the text a distraction and intrusion, an impediment to their reading and newsgathering. As the Stanford/Poynter (2008) study has measured, the online newspaper reader ignores all of the editorial and advertising visual clues and initially goes directly to the top left corner of a Web page to begin reading. Web users employ a process of selective disregard when engaging with an online interface and go directly to the place where they expect to find the information they require. This was a coping strategy of my study group, a new form of active reading in early development.

Newspapers and magazines have large diverse audiences with conflicting needs when accessing news, comprehending it and retaining pertinent information. Neuman, Just and Crigler, (1992) found that the media's perception of how news should be framed for newspapers, magazines and television, was not always accurate, for example the misconception that television was not the appropriate medium for complex issues. They discovered that television framed complex subjects more effectively than print. The online reader requires a degree of technological proficiency to navigate a newspaper or magazine website. While this does not need advanced 
computer skills, the tasks that are required in some part determine the look of a website. The simpler and more intuitive the presentation, the more it draws on established protocols, the easier the reading experience becomes.

The London Guardian, first published in 1821, was one of the first newspapers to use data in a visual form, in tables, as a service to its readers. The Guardian is a respected source of news in Britain and through its website, the English speaking world. It has been recently redesigned from a broadsheet into a format termed Berliner, a longer version of the tabloid format based on the German newspaper of that name. Its design is simple, modular and easy to access. Its website which follows the design and layout of the newspaper is an orderly and accessible online news source. Under the newspaper's nameplate a list of the content sections is displayed. Below that is a news feature that links to breaking news stories as they develop. The content of the sections, news business, sports, politics etc., is divided vertically into two parts, current news and events and an index of the complete newspaper. A column on the far right consists of small advertisements and promotions and a text index of the newspaper's additional content.

The design is busy but neither cluttered nor complex. It acknowledges that the most important spot on the screen is the top left corner where the lead news story with its typographic hierarchy of headline, sub-headline, byline and story index sits. The typographic treatment gives the reader cues as to the importance of a story in the same way as the print edition. As Tewksbury and Althaus (2000) have noted, the typographic cues of print newspapers, create a more cognitively engaged reader who recalls more details of stories they have read. The Guardian has successfully transferred this process to the Web. Hyperlinks to other content inside the newspaper and to other sources are infrequently used, which encourages the reader to remain focused on the story without wandering to other ancillary background materials.

The newspaper publishes the exact same story content on its website and in print editions. On the Euro Vegas news story that was used in the study the photograph was the same in both media. The arts item on Henri Matisse in the print edition had one of his later paintings and two small 
paintings of other exhibits the Tate gallery was planning for 2014. The layout of the website edition replaced these with a photograph of the artist at work. The space constraints of computer screen could not accommodate a large vertical painting that would prevent text appearing onscreen, above the fold. A Guardian monitored and edited reader comments section runs at the bottom of every major story. Registration is required to participate in this dialogue.

The Economist is a London based newsmagazine with a North American edition that in addition to publishing European news adds a US perspective. The magazine's design is simple with small photographs, informational graphics and charts supporting the text that dominates the page. Its website's homepage has a large photograph of the cover story, which is accompanied by a set of cover-lines that sell the most important stories in that week's edition. In a similar way to The Guardian the top left column is reserved for news stories, breaking news, and updates of the magazine's print edition. The centre column is the content of the current issue with a typographic hierarchy modeled on the print edition. The column on the right hand side consists of advertisements, promotions and blog postings.

The inside website pages follow a simple design, a banner advertisement with The Economist's title-piece and a set of links to sections below. A single, wide column of text is supported by single photograph. Near the end of articles an inset sidebar links the reader to related previously published articles on the same subject. The advertising and promotions are similar in structure to the homepage. Of the stories tested in the study, in the print edition, one story on fast food had a photograph and chart. The other story on HIV and AIDS had no art content. In the web edition the photograph and chart were used on the fast food story but no art was added to the HIV/Aids article. It must be concluded that the magazine's editors did not feel that it was necessary to add a visual image or chart, relying on the strength of the writing to engage the reader. The story content was the same in print and online.

Despite being less elegant and typographically precise in its online edition than The Guardian, The Economist successfully transferred the print typographic cues to its website. The study group 
noted that the publications were superior in presentation to other online offerings where raw HTML text impeded the reading process.

The New Yorker, the iconic English language weekly magazine has developed a tablet edition of its print edition. The study used the iPad version, which unlike a laptop computer screen presents the content in a vertical view, similar to the print magazine. If viewed on an iPad Mini, the format presents a single horizontal page with advertisements reconfigured to a landscape view. The New Yorker has rejected the magazine spread, the codex, in favour of a single page tablet view. The user scrolls horizontally through the magazine viewing single pages of editorial and single page advertisements. When the reader selects an article she moves vertically through complete single pages to read. The text is set and cannot be altered, enlarged or in any way distorted. The editors do not give the reader any control over of content display. A single column set in the magazine's proprietary typeface, a customized Caslon font, is the page layout. It is simple and elegant. When the reader has completed a story, or if they wish to move to another article, they simply move the page horizontally to the right and the next article is presented. The transition is in effect moving to the next page seamlessly, without actually turning the page. When asked about the tablet reading experience compared with the printed magazine one participant felt that it was simply a series of static PDF pages strung together. Others, remarking on the intuitive reading process, with the advertising pages as in print being an intrinsic part of the design, noted that it was a pleasant experience, much like print. No frantic advertising messages and no irritating hyperlink prompts.

Zambarbieri and Carniglia (2012) found that there were significant differences in the reading process between the PC and the iPad and Kindle eReader. This study found that there was no measurable difference in reading between the PCs, Apple laptops running on its operating system and the iPad. While the study did not set out to measure this, further investigation will be required to test Zambarbieri and Carniglia's research. 


\section{The Study's Structure}

\section{Methodology}

Research questions:

- Is the on-line reading process similar to reading the printed page as measured by the reader's comprehension and retention of information? If not, why and how do they differ?

- What reading strategies that differ from print do readers adopt when reading on-line? 
This study relies on a combination of quantitative and qualitative research. Qualitative research is exploratory and is used to explain a topic when the variables and theory base are unknown.

Creswell (2009) states that the characteristics of a qualitative research problem are: the concept is immature due to conspicuous lack of theory and previous research; available research may be inaccurate, inappropriate, incorrect or biased; a need exists to explore and describe a phenomenon and to develop theory or observe the nature of the phenomenon. These situations, Creswell concludes, may not be suited to quantitative measures.

The two content experts who assisted the study's lead investigator were a publisher with extensive experience in magazine print and online publishing and a financial writer and editor. All three reviewed news and opinion texts from three sources, The Guardian newspaper (Exhibits 1-4), The Economist news magazine (Exhibits 5-8) and The New Yorker magazine (Exhibits 912). 


\section{Gambling mecca brings jobs to recession-hit Spain, but anger grows over £8bn EuroVegas}

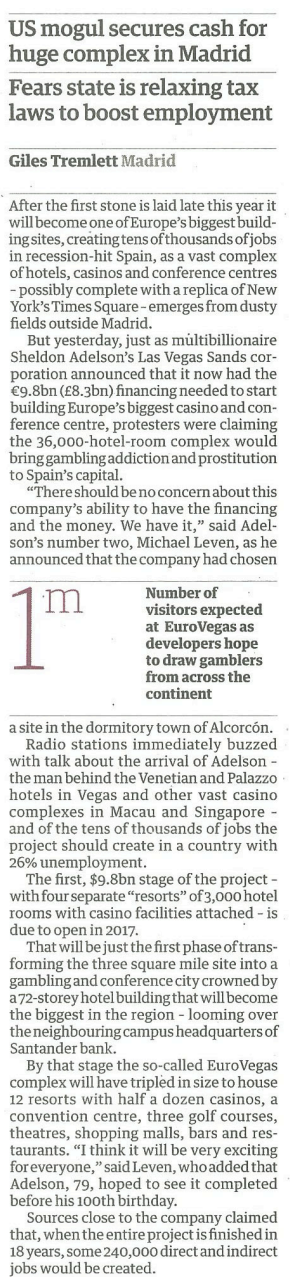
jobs would be created.

HMV chief laid off
amid more job cuts Press Association

HMV boss Trevor Moore was among the cies was confirmed at the failed music chain. Moore was one of 60 staff axed by
administrators Deloitte yesterday across HMV's head office network at Eastcastle The job losses come on top of an announcement earlier last week that 660 months, leaving 930 staff $f$ aing redundancy. Moore's exit comes weeks after he said he was "convinced" the future of the chain could be secured.

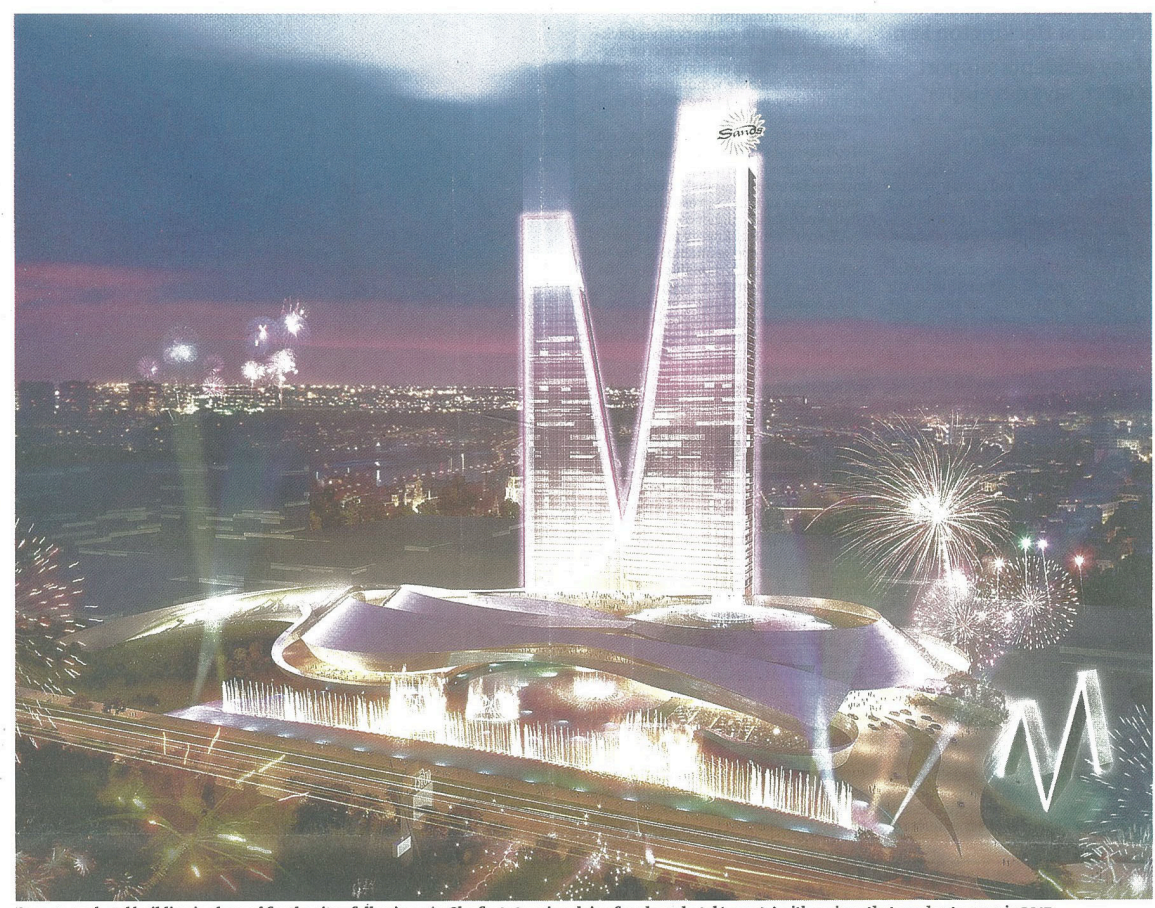

A 72-storey hotel building is planned for the site - following a $\$ 9.8 \mathrm{bn}$ first stage involving four huge hotel 'resorts' with casinos that are due to open in 2017

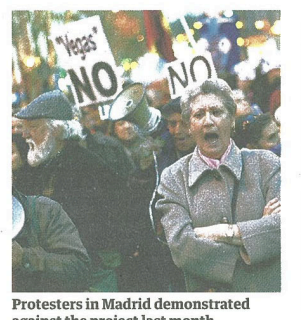

"We are building four resorts in the Ignacio Gonzalez virtually promised that bedrooms in each resort and the attendthejob-creating capacity to the company's projects in Singapore and Macau. "Singapore, which is about the same size as one of these [12 eventual resorts], employs
approximately 10,000 people directly and 10,000 more indirectly." ABC newspaper ran pictures from the EuroVegas project tit claimed hadbeen pre-
sented to local government officials byth company, hlowing two Shatdlike twin skyscrapers said to be 250 metrestall that appear to represent one of the "resorts"
The complex will reportedly also include The complex will reportedly also incl
a copy of New York's Times Square. Protestersin waject domonth

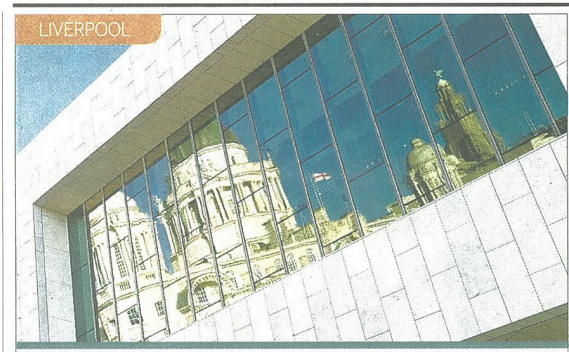

¿xolore custrurat England

Discover a side you never knew existed

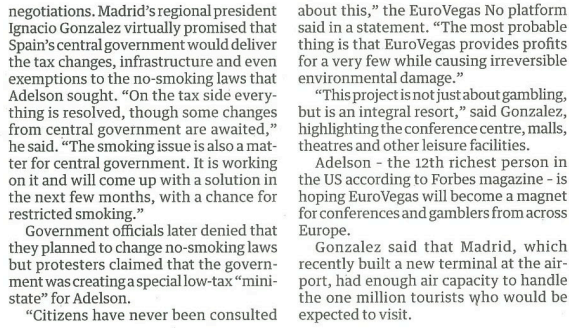

Citizens have never been consulted expect

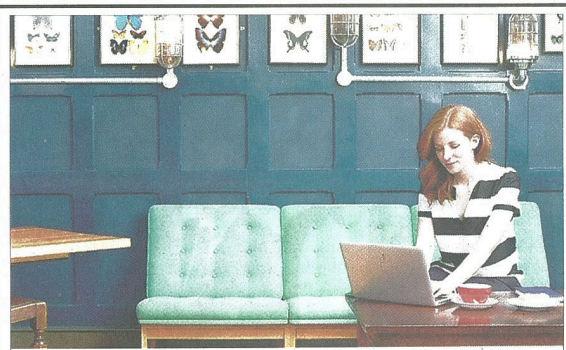

Access all areas

Smartsolutions for modern lives

Exhibit 1: The Guardian, Euro Vegas print 
News $\mid$ Sport $\mid$ Comment $\mid$ Culture $\mid$ Business $\mid$ Money $\mid$ Life \& style $\mid$ Travel $\mid$ Environment $\mid$ Tech $\mid$ TV $\mid$ Video $\mid$ Dating $\mid$ Offers $\mid$ Jobs

\section{News > World news > Spain}

'EuroVegas' gambling complex to be built near Madrid after $£ 8.3$ bn secured

Europe's biggest casino and conference centre to bring jobs, but also fears of gambling

addiction, prostitution and mafia activities

Giles Tremlett in Madrid

The Guardian, Friday 8 February $201319.59 \mathrm{GMT}$

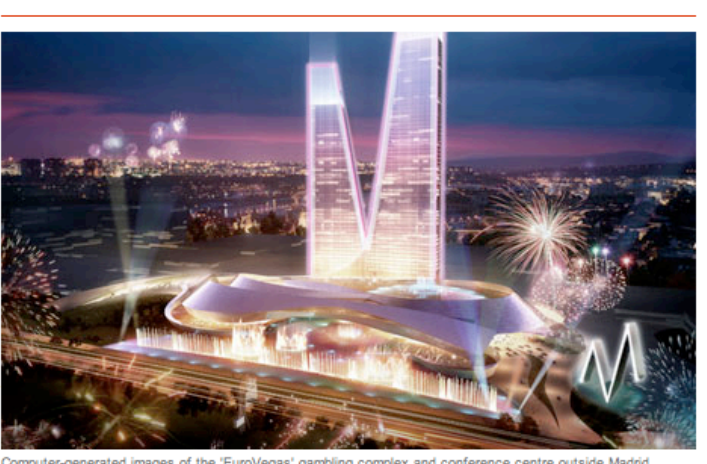

After the first stone is laid late this year it will become one of Europe's biggest building sites,

creating tens of thousands of jobs in recession-hit Spain, as a vast complex of hotels, casinos and conference centres - poss by
dusty fields outside Madrid.

But on Friday, just as multibilitionaire Sheldon Adelson's Las Vegas Sands corporation announced that $t$ now had the $69.8 \mathrm{bn}$ (28.3bn) financing needed to start building Europe's biggest casino and addiction and prostitution to Spain's capital. ff $^{\text {Share }} \sqrt{33}$

y. Tweet 139

$8+1 \sqrt{14}$

in share 3

$\triangle$ Emal

\section{国国}

Article history

World news
Spain. Europe

UK news

Gambing

Related

\section{May 2013}

Keeping up with Teresa Forcad

3 May 2013

May 2013

tisen

1 May 2013

May Day protests draw
thousands of workers across

1. May 2013

1 May 2013
It's Spain v Germany - in footbalt

Silence you'll love.

Deals you'll desire.
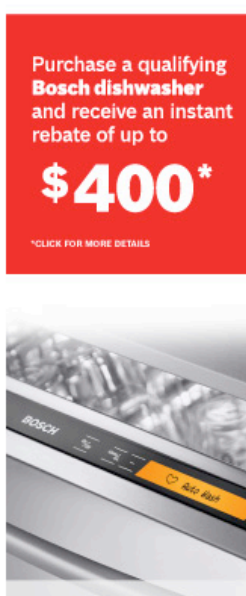

(ii) $\mathrm{BOSCH}$

Invented for life

Exhibit 2, The Guardian, Euro Vegas web 


\section{National}

\section{Tate makes the cut with Matisse}

Artist's late works, using scissors and coloured paper, to be shown together after 60 years

Charlotte Higgins
Chief arts writer

The extraordinary works Henri Matisse created during the last period of his

paper, including his famous Blue Nudes

-are to be exhibited at Tate Modern

next spring.

exhibition bf these comprehensive works

held, with 120 on show, including his

Large Composition with Masks from the

National Gallery of Art in Washington,
Memory of Oceania from the Museum of

Modern Art in New York, and Tate's ow
The Snail. The works were displayed

together by the artist in his studio, and

will be seen together again for the first

Matisse began to make cutouts in

1943, according to curator Nicholas Cul-

inan, after an operation in his early 70

that he was living on borrowed time. At

first, the impulse was pure expedience

the works could be made much more

time, "he began to realise the potentia

in the method, and stopped painting,

choosing to focus on the cutouts, saic

ated he felt; how he had been given

second life.

With assistants colouring the paper to precise specifications and then helping

"make cutouts with a rapid gesture with the scissors, incredibly quickly," said Cullinan. He was also "fastidious an

work until it was exactly right.

He became so entrenched in this way

of making art that "his work rate accele

ated ... He would work aroutnd he clock

being really put through their paces by
him. He was still working in 1954 , two

days before he died.

They were extraordinarily forward-

installations or environments than

paintings; and they seem very contem-

phow is to reconsicer them in this list,

said Cullinan. "They were a way of col-

lapsing line and colour; at the same tim

they were a kind of sculpture - carving

Tate Modern's 2014 lineup will also

include shows devoted to two recen

departed major figures, Richad Hamil-

ton, the father of British pop art, and the

also be an exhibition devoted to the Ru-

sian constructivist Kasimir Malevich.

At Tate Britain, there will be the first

tion devoted to Turner's late period, air

one exanining the cuitural contibution of the critic Kenneth Clark. The sculpto Phyllida Ba.low, known for her works to make new work for the Tate Britain Commission. At Tate Liverpool, a show devoted to Mondrian willinclude a

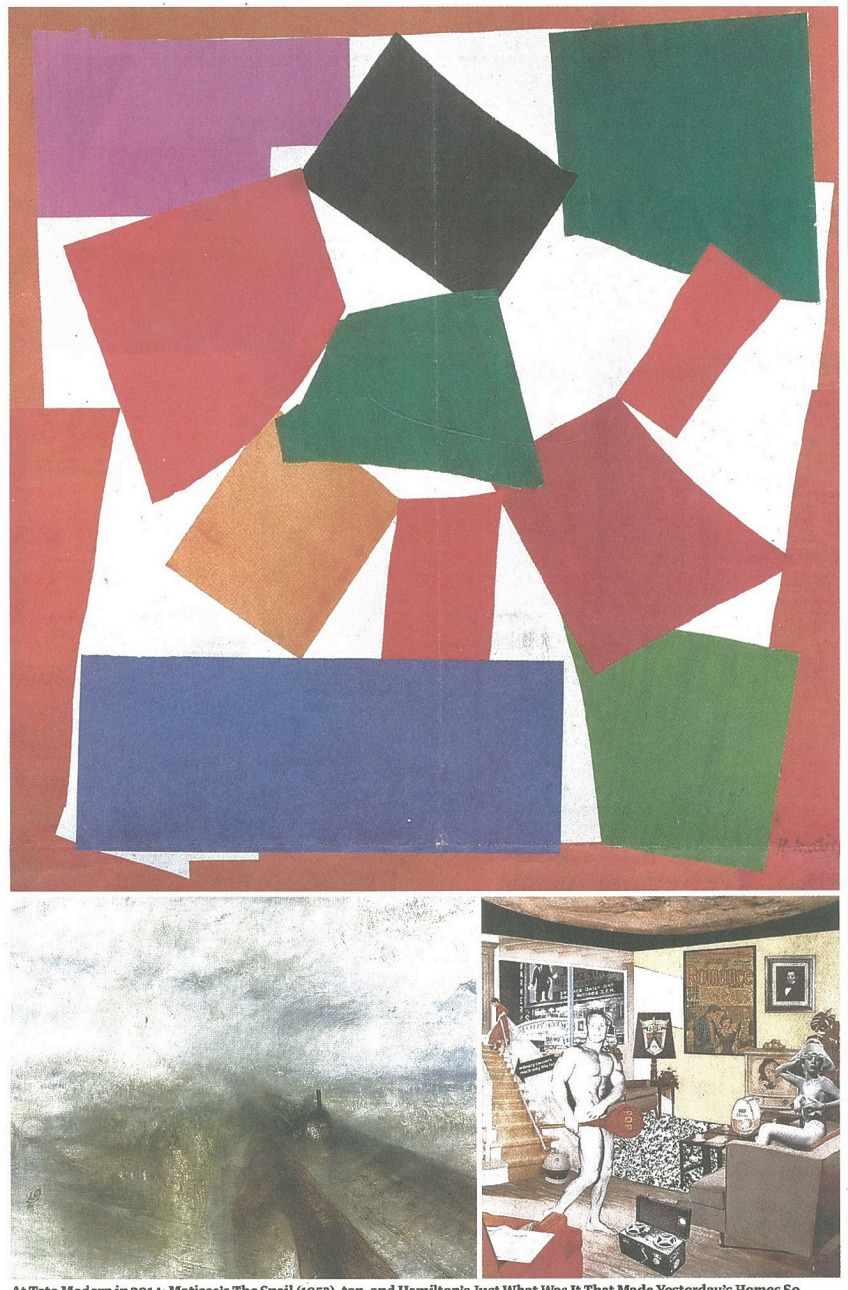

At Tate Modern in 2014; Matisse's The Snail (1953), top, and Hamilton's Just What Was It That Made Yesterday's Homes So

Why posh

people

mind about 'toughness of mind'

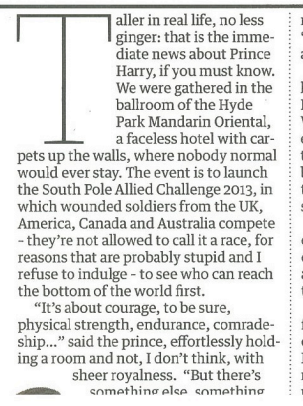
nobody ever built an empire saying,
"but the South Pole is incredibly cold
and inhospitable".

"Teams of our wounded will manhaul sledges on skis", explained Ed Wounded. It's "sto show the world the tion of the men and women who have been wounded while serving our counsupport we owe them". I get all that. It is good to be reminded of the hardship they endure on our (sort anchar, even hardship is a curious way to go about it.

I accept, even while I admit I do no fully understand, that posh people ar obsessed with the poles. That's why rather than (or maybe as well as) to $\mathrm{Ch}$

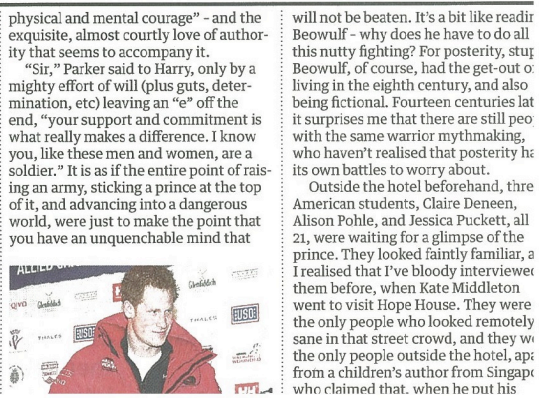

physical and mental courage" - and the
exquisite, almost courtly love of auth ur support and commitme r." It is as if the entire point of will not be beaten. It's a bit like readir

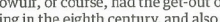
ing fictional. Fourteen centuries lat with the same warrior mythmaking, own battles to worry about. merican students, Claire Deneen, , were waiting for a glimpse of the ealised that I've bloody interviewe ent to visit Hope House. They were ane in that street crowd, and they w rom a children's author from Singap
rho claimed that, when he out his
Sacré bleu! French leave loses appeal for Britons

Esther Addley

From Henry V to Peter Mayle, Britonsh: asm in order to claim a small corner 0 But figures published by the off
of themelos nation's love affair with the chateaux the Dordogne and the patisseries of $P_{i}$
maybe on the wane, with visitornumb The ONS's annual survey of tra ends found that British visitorsto Fra numbered 8.8 million in 2012, well do moregallingly for the Gauls, while visit North Americawerealso down last yeal nditors rise with 23 millioner of Brit siting Spain than France last The reasons for the cooling of rench love affair were not clear, $\mathrm{s}$ NS and the report's author Thanks combination of the Olympics, the Jubi and the wettest April to June on reco Spanish visitors fell by 1.2 millio 2009/10, but "what's happened there rshave clawed their way back to wh hey were". France has not yet rever
its decline. Jeremy Waldron, director of market at the Association of British Travel Org
isers to France, linked the count ccline in popularity to the financial $c$ r amilies may be seeking cheaper deal: e package destinations in which Sp nation," he said. "You go to to France some extent, for Frenchness, not just he destination." woes as boosting their pys finan rance's expense. "With the eurozi crisis Spain and Italy ... have beco Moore, chairman of the Associatior Independent Tour Operators, while France prices continue to rise".
In addition, he said, "local governm In addition, he said, "Oocalgovernme
had stopped the massive hando Ryanair and the like demand to fly destinations, "leading tolow-cost carr
pulling out of some routes to France. waldron sees the olympics as a fac suggestingtheramily and campingsect
which saw a slump were hit by fami. staying in Britain to watch the Games.
The overall number of trips abroad The overall number of trips abroad
UK residents fell by 0.5\% in 2012. Ince ing tourist numbers last year wereu
$0.9 \%$ on 2011 , although the numbe those who came during the third quar down on the previous year But in because those visitors, a total of $471, \mathrm{c}$ came specifically for the Games, sp more than in the previous year on a age, earnings frop vists to Bitain ros dis nutty fighting? For posterity, stu

Exhibit 3, The Guardian, Matisse print 


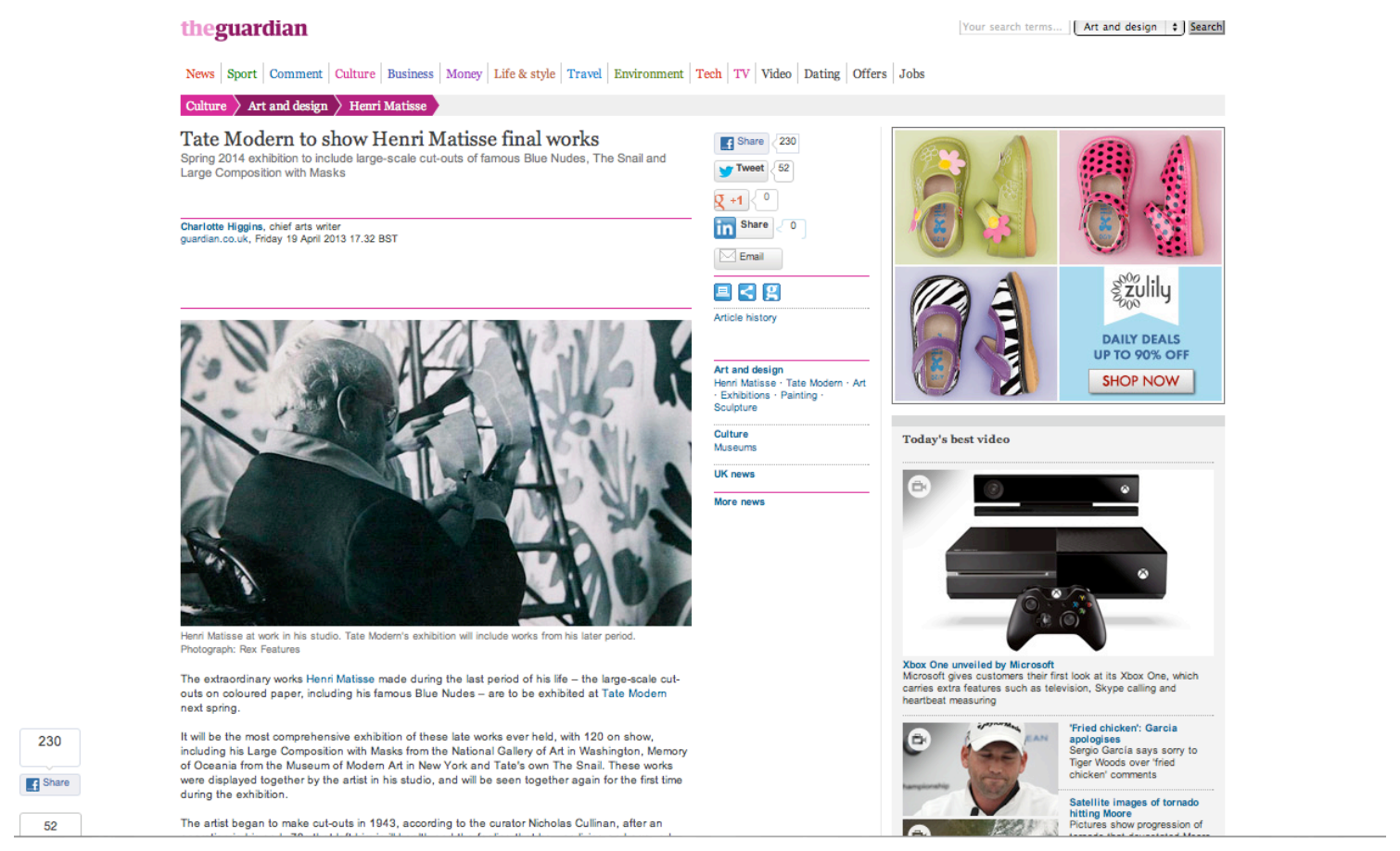

Exhibit 4, The Guardian, Matisse web 
The Deepwater Horizon disaster

\section{Spills and bills}

The bad news for BP keeps coming

$A$ FTER the Deepwater Horizon oil rig ex$\mathrm{A}_{\text {ploded in 2000, killing } 11 \text { workers and }}$ spewing a lake of oil into the Gulf of Mexi$c 0$, BP knew it would be punished severely. So far, the British oil firm has set aside $\$ 42$ billion to pay fines, compensate victims and clean up the mess. Of this, some \$36 billion has already been paid out or earmarked. America has also temporarily barred the company from bidding for federal contracts.

In all, nr has shelled out \$14 billion to stop the spill and restore the coast to the way it was. It has paid out or earmarked $\$ 17.5$ billion to compensate individuals and small businesses, plus another $\$ 4$ billion to settle criminal charges with the Department of Justice. It has also set aside $\$ 3.5$ billion to pay penalties for oil leaks under America's Clean Water Act.

These have yet to be determined. A civil trial, set to begin on February 25th in New Orleans, will apportion blame for the accident, determine how much oil gushed out and apply financial penalties. The federal government is demanding $\$ 21$ billion in compensation for spilt oil. To get that much, it must prove BP was "grossly negligent". It must also persuade the court to accept its estimate of the size of the leak, rather than BP's much lower figure.

As if that were not enough, BP's annual results, released on February 5th, harboured another nasty surprise. Tucked away on page 42 were details of hefty new claims against the oil giant. Alabama, Mississippi, Florida and Louisiana are demanding $\$ 34$ billion for economic losses and property damage. These mainly relate to tax revenues allegedly lost as a result of disruptions to businesses, says BP.

The oil giant knew that a bill was in the post a three-year statute of limitations will soon expire. However, it was not expecting the bill to be so big. BP disputes the way the sum has been calculated and is ready to fight the claims in court. It reckons that the states will have a tough job substantiating their calculations of forgone taxes.

Both claims seem likely to be settled out of court. Stuart joyner of Investec, a broker, points out that going to trial is in the interests of neither side. The judge, already testy after delaying the trial by four months to avoid a clash with Mardi Gras and the Super Bowl, says he would prefer a settlement, something private plaintiffs have already managed. The government has

\section{Fast food in China Yucky Kentucky}

Yum! Brands stumbles in China

66 UR food is perfectly safe to eat." From the company that once boasted that its fried chicken was "fingerlickin' good", this is hardly a bold sales pitch. But Yum! Brands, the owner of krC, Pizza Hut and Taco Bell, has good cause to sound defensive. A food safety scandal in China, its most important market, refuses to blow over.

An exposé in December on CCTV. China's national broadcaster, claimed that local suppliers to KFC had stuffed its chickens with excessive antibiotics. Tha prompted an official investigation, and outrage on Chinese social media. During an earnings call on February 5 th to discuss its fourth quarter results, Yum! executives stressed the positive: worldwide sales grew by $5 \%$ in 2012 , and the firm opened 1,976 new restaurants. The Chinese regulator has decided not to take further action against Yum!, though its suppliers are still under the microscope.

Yet the firm had to acknowledge that KFC sales in China fell by a staggering $41 \%$ in January. Overall, same-store sales for Yum! outlets in China fell by $6 \%$ in the fourth quarter of 2012 , versus the same period a year ago; the comparable figure

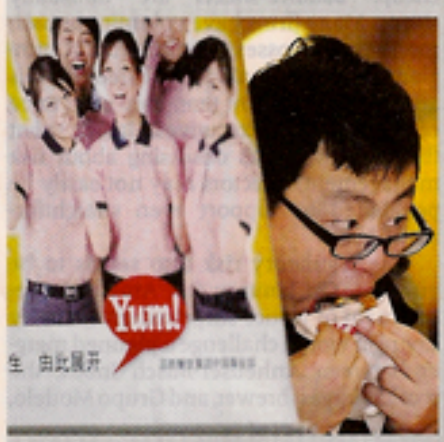

Enjoying the glamorous Western bifestyle

an attempt to nail $\mathrm{np}$-some 4,500 public servants have worked full-time on the mat ter. If the case comes to trial, the oil gian will probably argue that the government's regulatory regime was partly to blamethat $\mathrm{BP}$ followed the rules but the rules were not up to scratch.

nip would far rather end the matter quickly and get on with its business. The uncertainty over the final bill is weighing down its share price. And its sheer size is daunting. If all the daims against it are up.
Not so yummy

Yum! Bands' same-rsore sale

Sthunge on priviod yeat

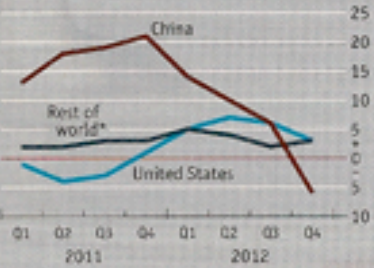

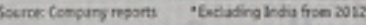

in 201 was a $21 \%$ rise (see chart). Yum! will have to revise its global eamings target for 2013 "significantly".

Yum! has bet heavily on China, open ing 889 new stores there last year. Stores elsewhere are typically low-margin franchises, but in China Yum! tends to own them. So in good times it pockets fat margins: China last year made up half of its $\$ 4.2$ billion sales and two-fifths of its $\$ 500 \mathrm{~m}$ operating profits. In bad times, however, its pain in China is magnified.

Undaunted, Yum! says "it is full steam ahead" for further investments in China. It is launching a marketing campaign to build on its "cool, hip" brands. It is push ing its suppliers to improve quality. Given its clever efforts to cater to local tastes (menus offer consee and egg tarts) and its successful recovery from the sars crisis, it should rebound.

Still, it will not be easy. The firm's scorching growth in China was already cooling off before this setback. After a string of food scandals, Chinese diners seem increasingly unwilling to forgive offenders. Nor are they still willing to give foreign brands the benefit of the doubt, Yum! bosses admit: "We don't know how long it will take us to recover."

lion or so. By way of comparison, Saddam Hussein's Iraq was ordered to pay reparations of \$ $\$ 2$ billion ( $\$ 88$ billion in today' money) for invading Kuwait.

One reason why a settlement has proved elusive is that the case is so com. plex. It involves three pieces of legislation and several layers of federal, state and lo. cal government with precious little co-or. dination between them. For example, вP notes that 11 tiny Louisiana parishes have made a separate claim for damage to local

Exhibit 5, The Economist, Yucky Kentucky, print 


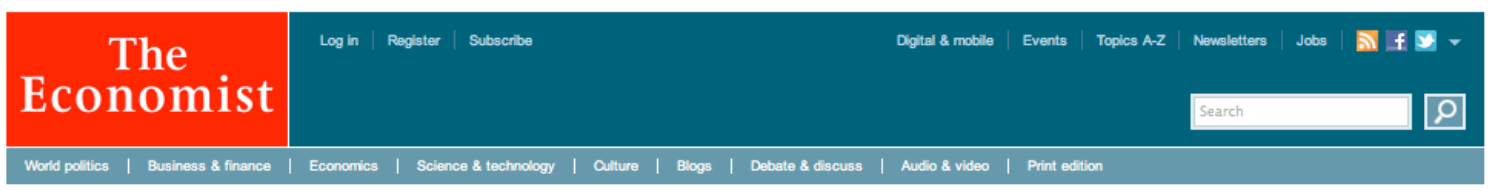

Fast food in China

Yucky Kentucky

Q Comment (23)

直 Print

Yuml Brands stumbles in China

Feb 9th 2013 | SHANGHAI | From the print edition.
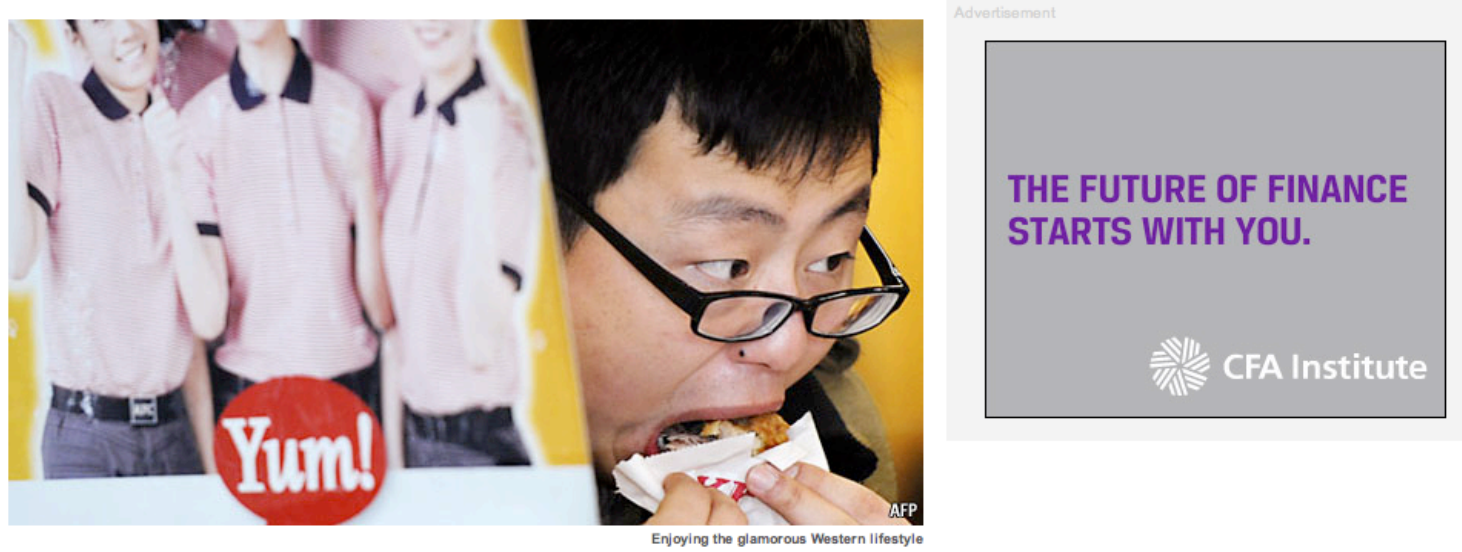

"OUR food is perfectly safe to eat." From the company that once boasted that its fried chicken was "finger-lickin' good", this is

hardly a bold sales pitch. But Yum! Brands, the owner of KFC, Pizza Hut and Taco Bell, has good cause to sound defensive. A

food-safety scandal in China, its most important market, refuses to blow over:

An exposé in December on CCTV. China's national broadcaster, claimed that local suppliers to KFC had stuffed its chickens with

nnomist.com/news/business/21571467-yum-brands-stumbles-china-yucky-kentucky", completed 143 of 145 items

Exhibit 6, The Economist, Yucky Kentucky, web 


78 Science and technology
Meteorology

\section{Counting raindrops}

How to use mobile-phone networks for weather forecasting

EORECASTING the weather requires $\mathrm{F}$ huge quantities of data. Many of these data are collected by high-tech means such as satellites and radar, and then crunched by some of the world's fastest supercom puters into predictions that are far more accurate than they were 20 years ago. But low-tech tools are important too-especial ly old-fashioned rain gauges, which are nothing more than tubes with funnels fixed to places such as rooftops.

Each technique has its upsides and downsides. Radar and satellites can cover swathes of land, yet they lack detail. Gauges are much more accurate, but the price of that accuracy is spotty coverage. Now, though, Aart Overeem of the Roya Netherlands Meteorological Institute and his colleagues reckon they have come up

\section{HIV and AIDS}

\section{Till death do us part}

Putting numbers on infidelity

NE of the problems of dealing with a sexually transmitted disease, such as AIDS, is that people routinely lie about their indulgence in the sorts of behav. iours which pass it on. That makes knowing where to put your effort harder than it need be. And in no area do people lie more than on the question of infidelity. The naive outsider might be forgiven for thinking that infidelity was likely to be an important way that Brv, the virus which causes Ams, is spread. Until now, how ever, that was mere supposition.

Steven Bellan of the University of Texas at Austin haschanged this, with a paper in the Lancet. Using data likely to be more reliable than answers to the question: "have you been cheating on your wife/husband?" he and his col. leagues have worked out how much HIV infection is caused by adultery. The an swer, as might be expected, is "a lot".

Dr Bellan and his colleagues reached this conclusion from a survey of 27,000 married or cohabiting couples in 18 Afri: can countries. The survey looked at who in these couples was infected, how long the couple had lived together, and the age at which each member of each couple first becarne sexually active. Most people do not routincly lie about these things, with another way to keep an eye on the rain. It offers, they believe, both broad coverage and fine detail. Best of all, it relies on something that is already almost omnipresent-the mobile-phone network.

Their scheme starts from the observation that main can make it harder for certai sorts of electromagnetic radiation to trave through the atmosphere. Measure this im pedance (and scrub out any other source of variation) and you can measure how rainy it ic. The researchers do not measure the strength of mobile-phone signal themselves. Instead, they piggyback on something that mobile networks already do, and measure the strength of the microwave links that base stations use to talk to each other.

The idea itself is not new, and there have been trials in recent years. But, as they report in the Proceedings of the Nationd Academy of Sciences, Dr Overeem and his colleagues have successfully applied the technique to an entire country. Using dati from around 2,400 links between base-stitions belonging to $\mathrm{r}$-Mobile, one of the Netherlands' three mobile-phone operators, they were able to generate a rain map of the whole kingdom every 15 minutes.

except for age of first sexual encounter. The researchers took account of that by showing that claims as much as a year at variance with the truth would make little difference to the outcome.

Dr Bellan plugged the results into a mathematical model that also takes account of ruv's prevalence in a country and how long people there live once they have been infected. This let him estimate what proportion of HIV infections had come about by one or other member of a couple having been unfaithful, as opposed to having been infected before the couple got together, or having caught the virus from a partner so infected.

The answer was between $27 \%$ and $61 \%$ for men and between $21 \%$ and $51 \%$ for women. What can be done about that is a different question. Early in the AIDs epidemic, the virus was spread by what might be termed "long distance" infidelity. Lorry drivers and migrant miners, lonely and far from home, were the vectors. Those groups, however, could be made the target of campaigns designed to ask them to think about what they vere up to and to be more careful about it. What Dr Bellan has uncovered looks more quotidian-and thus much harder to deal with.
Like all the best science, the idea is both technically elegant and practically useful. Dr Overeem points out that simply coming up with another way to measure rainfall is handy by itself, since it allows better crosschecking of existing methods. There are other advantages, too. Coverage is one. Even in rich countries with well-financed weather forecasters, there are likely to be far more mobile phone base stations than rain gauges. That is truer still in poor countries, where rain gauges are scarce and ndar often nonexistent, but mobile phones common. The GSM Association, a mobilephone trade group, estimates that $90 \%$ of the world's population lives within range of a base station.

Another boon is that network operators tend to keep a close eye on their microwave links. Although the researchers were able to obtain data only every 15 minutes, some firms sample their networks once a minute. That means rainfall could, in principle, be measured almost in real time, something that neither gauges nor radar nor satellites can manage.

The technology is not perfect: snow and hail are harder than rain for micro. waves to spot, for example. And there are other caveats. Mobile networks are dens. est in urban areas, which are also the places most likely to have meteorological equipment already. Even in the rich, urbanised Netherlands, coverage outside cities was noticeably patchier. But that might eventually prove to be a boon, for if the technology becomes widespread then weather forecasters might contribute to the cost of installing base stations in coverage blackspots-something for which the $10 \%$ of humanity not yet within range of a mobile-phone mast might be thankful.

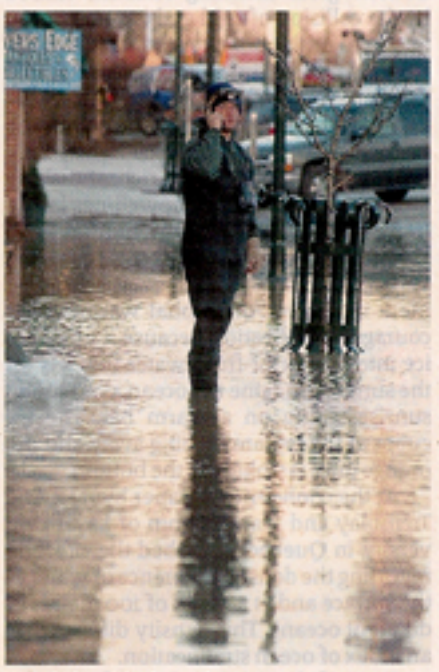

Yes, it is a bit damp here...

Exhibit 7, The Economist, HIV AIDS, print 


The
ECOMOMist
Log in | Register | Subscribe

HIV and AIDS

Till death do us part

Q Comment (4) 次 Print

Putting numbers on infidelity

Feb 9 th 2013 | From the print edition

ONE of the problems of dealing with a sexually transmitted disease, such as AIDS, is that people routinely lie about their indulgence in the sorts of behaviours which pass it on. That makes knowing where to put your effort harder than it need be. And in no area do people lie more than on the question of infidelity. The naive outsider might be forgiven for thinking that infidelity was likely to be an important way that HIV, the virus which causes AIDS, is spread. Until now, however, that was mere supposition.

Steven Bellan of the University of Texas at Austin has changed this, with a paper in the Lancet. Using data likely to be more reliable than answers to the question: "have you been cheating on your wife/husband?" he and his colleagues have worked out how much HIV infection is caused by adultery. The answer, as might be expected, is "a lot".

$\mathrm{Dr}$ Bellan and his colleagues reached this conclusion from a survey of 27,000 married or cohabiting couples in 18 African countries. The survey looked at who in these couples was infected, how long the couple had lived together, and the age at which each member of each couple first became sexually active. Most people do not routinely lie about these things, except for age of first sexual encounter. The researchers took account of that by showing that claims as much as a year at variance with the truth would make little difference to the outcome.

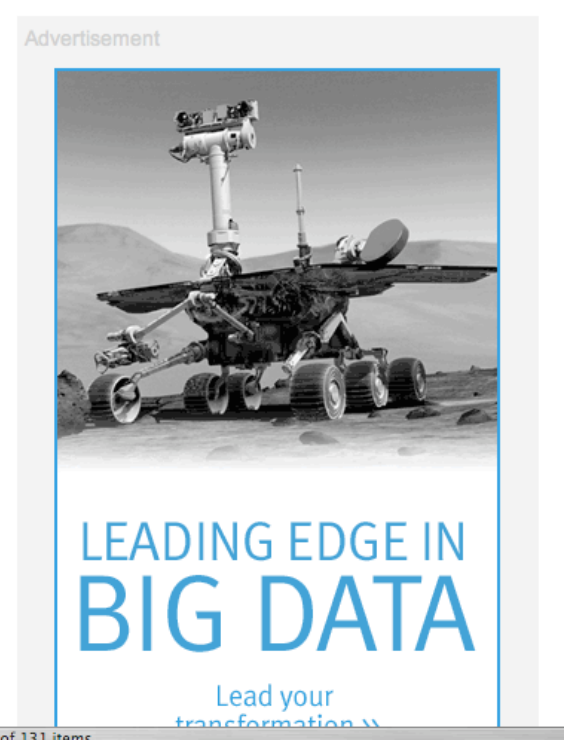

Exhibit 8, The Economist, HIV AIDS, web 


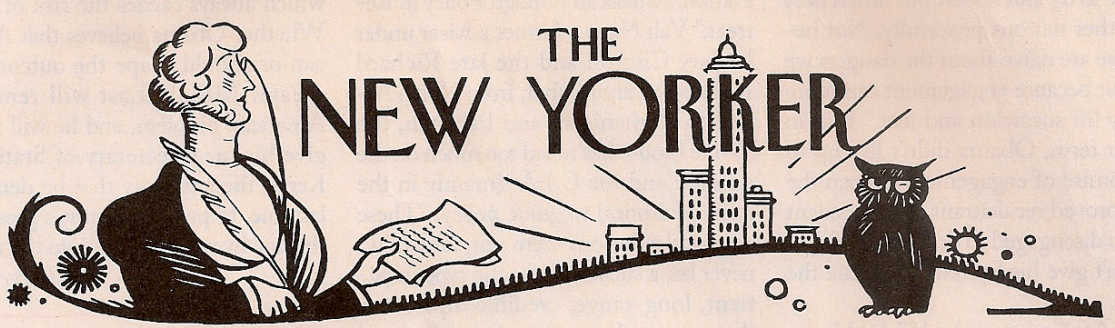

THE TALK OF THE TOWN

COMMENT

LONG ENGAGEMENTS

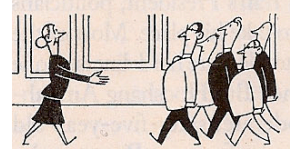

After four exhausting years, Hillary A Clinton leaves the State Department with an impressive record of air miles logged, town-hall meetings held, important but neglected issues highlighted, international crises defused, gaffes avoided, citizens of the United States and the world wowed, and White House policies capably carried out. When Clinton and President Obama recently sat down for an interview on " 60 Minutes," they all but held hands, swearing deathless affection and respect, and they seemed to mean it. But Clinton was denied the chance to be a truly great Secretary of State - another George C. Marshall or Dean Acheson-by both history and the President she served.

Last year, Denis McDonough, a top White Iouse adviser, described Clinton's role as "the principal implementer" of Obama's foreign policy. On a few occasions, her advice helped to tip the scalesthe 2009 surge in Afghanistan, which she strongly supported, was one-but she and her department were never trusted with the policy blueprints. From Iran and Israel to nonproliferation and human rights, the President has kept policymaking inside the White House, tightly held by a small circle of political advisers.
This shouldn't matter, except maybe to Washington insiders, as long as the policies were the right ones. By the standard of the Mippocratic oath, they have been. Judging from last fall's campaign, the biggest preventable foreign-policy disaster of Barack Obama's first term was the killing in Benghazi of the U.S. Ambassador to Libya and three other Americans. Benghazi was a tragedy for which the State Department bore much responsibility; but, after the Bush years, the rest of the Administration's record is no minor achievement. Obama and Clinton inherited two unwinnable wars, a toxic international atmosphere in which America was reviled where it wasn't ignored, and a badly

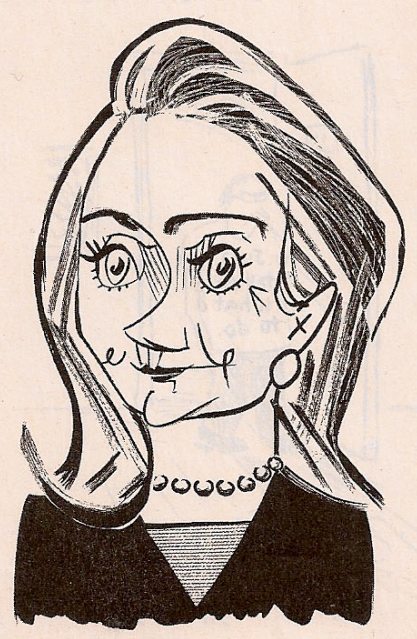

diminished stock of national power. The criticism that there is no encompassing "Obama doctrine" misses the point. Geopolitics today is too complex, messy, and various to be bent to America's will by an overarching doctrine like containment, or a massive initiative like the Marshall Plan, or a single breakthrough like Nixon's trip to China. A doctrine was what put the country in a deep hole; climbing out required restraint, flexibility, and opportunism. A first-term Secretary of State with one grand strategic vision wouldn't have matched the demands of the moment, which called for a fox, not a hedgehog. Clinton's true legacy might be the countless public events that she held from Lahore to Kinshasa, where thousands of ordinary people got to question the U.S. Secretary of State, and where the topic was often something like women's rights or access to clean water. These efforts were sometimes derided as soft, and marginal to real foreign policy, but Clinton - who is, after all, a politician-knew that she would have to be seen listening in order to help regain the world's respect. That and four years of carefully calibrated Presidential rhetoric and support for multilateralism have gone a long way to restoring America's legitimacy as the leading global actor.

If there is one idea that sums up Obama's approach to foreign policy, it's engagement. "We will extend a hand if you are willing to unclench your fist," he proclaimed in his first Inaugural, and in his second (which barely touched on foreign policy) he said, "We will show the

Exhibit 9, The New Yorker, Clinton, print 


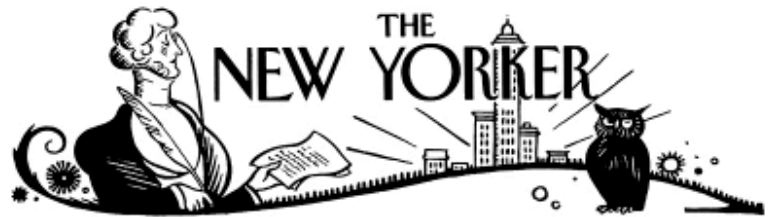 \\ THE TALK OF THE TOWN}

\section{COMMENT}

\section{LONG ENGAGEMENTS}

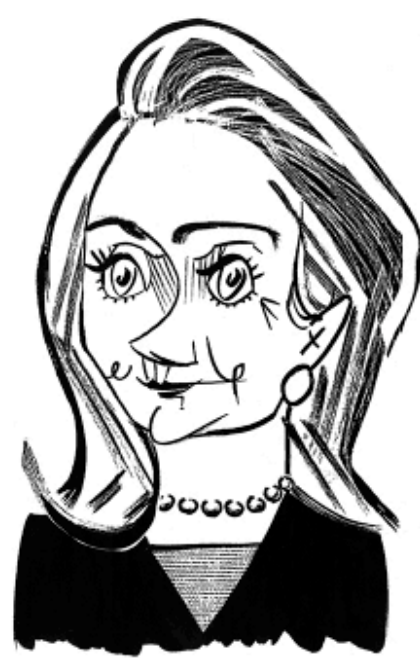

Illustration by Tom Bachtell.
DAILY COMMENT

Daily posts from newyorker.com.
A fter four exhausting years, Hillary Clinton leaves 1 the State Department with an impressive record of air miles logged, town-hall meetings held, important but neglected issues highlighted, international crises defused, gaffes avoided, citizens of the United States and the world wowed, and White House policies capably carried out. When Clinton and President Obama recently sat down for an interview on " 60 Minutes," they all but held hands, swearing deathless affection and respect, and they seemed to mean it. But Clinton was denied the chance to be a truly great Secretary of State- another George C. Marshall or Dean Acheson-by both history and the President she served.

Last year, Denis McDonough, a top White House adviser, described Clinton's role as "the principal implementer" of Obama's foreign policy. On a few occasions, her advice helped to tip the scales-the 2009 surge in Afghanistan, which she strongly supported, was one-but she and her department were never trusted with the policy blueprints. From Iran and Israel to nonproliferation and human rights, the President has kept policymaking inside the White House, tightly held by a small circle of political advisers.

This shouldn't matter, except maybe to Washington insiders, as long as the policies were the right ones. By the standard of the Hippocratic oath, they have been. Judging from last fall's campaign, the biggest preventable foreign-policy disaster of Barack Obama's first term was the killing in Benghazi of the U.S.

Exhibit 10, The New Yorker, Clinton, web 
THE FINANCIAL PAGE A CALL TO ACTION

Tast week, football fans across the 1 country committed a crime: they bet on the Super Bowl. Billions of dollars was wagered on the game, almost all of it staked by people who live in states where sports gambling is against the law. Like participating in an N.C.A.A. office pool, betting on the Super Bowl is an all-American pastime. But in most of the country it's illegal.

New Jersey voters want to change that. In 2011, they overwhelmingly approved an amendment to the state constitution making sports betting legal, and early last year the state legislature passed a law to that effect. Dennis Drazin, the lawyer who advises the Monmouth Park racetrack, announced plans to set up a sports book. There's just one hitch: the federal government. In 1992, Congress passed a law banning sports betting everywhere in the U.S. except in the four states that already had some form of it (Nevada, Delaware, Oregon, and Montana). Now the four major professional sports leagues, the N.C.A.A., and the Justice Department are suing to prevent New Jersey from going ahead with its plans. Drazin told me that he'd like to be able to offer some kind of betting in time for March Madness. But that can happen only if the judge overturns the 1992 law as an unconstitutional infringement on states' rights.

The constitutionality of the federal ban on sports gambling may be an open question. But there's little doubt that permanently, and arbitrarily, dividing the country into "betting states" and "non-betting states" was terrible public policy. "It's completely irrational," I. Nelson Rose, an expert on gambling law at Whittier Law School, says. "It's as if in 1929 Congress had decreed that a dozen states would be allowed to have sound in their movie theatres and all the other states would be able to show only silent films." That irrationality may reflect the country's deep ambivalence about gambling. Rose points out that, historically, the U.S. has oscillated between periods of permissiveness toward gambling and periods of crackdown. We're now in one of those permissive eras, which Rose calls "the Third Wave" of legal gambling. Betting has become ubiquitous, and a major source of revenue for states. Fortythree states and the District of Columbia have lotteries. All the states except Utah and Hawaii have commercial gambling in some form. And more than forty have racetrack betting. But sports bettingwhich, ironically enough, is much fairer than lotteries or slot machines and involves more skill - allows politicians to express their inner puritan.

Of course, politicians are also responding to the influence of the major professional sports leagues. The leagues insist that legalized betting will make people suspect that games are fixed, thus

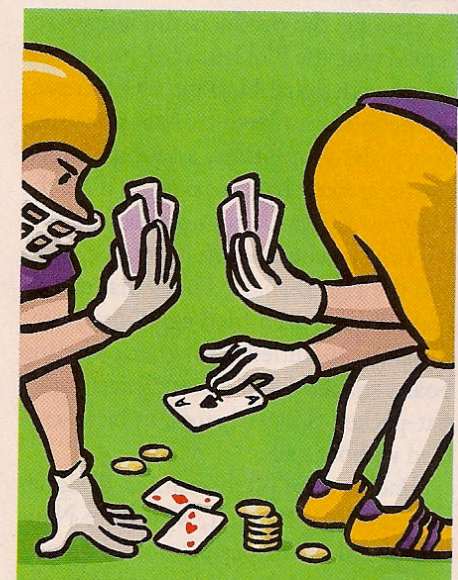

harming their brands. Yet in Vegas billions are wagered legally on sports every year, apparently without ill effect, and legal sports betting in Great Britain doesn't seem to dim anyone's passion for Premier League soccer. Moreover, as Drazin said to me, betting is already an integral part of sports in the U.S.: "If gambling is really hurting the leagues, why does every sports show talk about point spreads and favorites and underdogs? And why does every office in America have a pool on the N.C.A.A. tournament?" Indeed, it's likely that gambling makes sports more popular, not less. "We know that the début of 'Monday Night Football' really fuelled an explosion in sports betting," Rose told me. "And that in turn made 'Mon- day Night Football' more popular." Even the leagues seem to recognize this. They happily condone fantasy sports, which are, in effect, an attempt to predict on-the-field outcomes, and which have become an industry with more than a billion dollars a year in revenue.

The ban on sports betting does exactly what Prohibition did. It makes criminals rich. People still gamble, after all: the National Gambling Impact Study Commission estimates that more than three hundred billion dollars is bet on games annually. Legalized sports betting would bring in significant tax revenues for the states-Drazin estimates that Monmouth Park could take in a billion dollars in bets in its first year-and it would leave cops and prosecutors free to go after crimes with real victims. As for the concern that legalization would encourage shady behavior, the truth is that legal and regulated betting makes it easier, not harder, to spot things like point-shaving. One of the biggest college point-shaving scandals of the past twenty years was uncovered when Vegas bookies noted unusual betting activity on certain games and reported it to the authorities.

Rose says that the 1992 law is "plainly unconstitutional," and Drazin expresses confidence that it will be overturned. But, even if it's not, Congress should amend the law, and make it possible for states that want to legalize gambling to do so. As Rose notes, "Gambling has typically been a state issue, not a federal one." And, while states' rights has been used as an excuse to justify plenty of bad policies, the idea that certain matters are better handled at the state level remains an important one. Overriding states' rights and insisting on national legislation makes sense in many circumstances - but not when one state's decision has no obvious negative effects on other states or on the national economy. There's an obvious parallel here with the current wrangling between the federal government and states that have legalized marijuana. If New Jerseyans want to be able to place the occasional bet on an N.F.L. game, or Coloradans want to be able to get high, the rest of us should let them. There's no need to make a federal case out of it. - James Surowiecki 


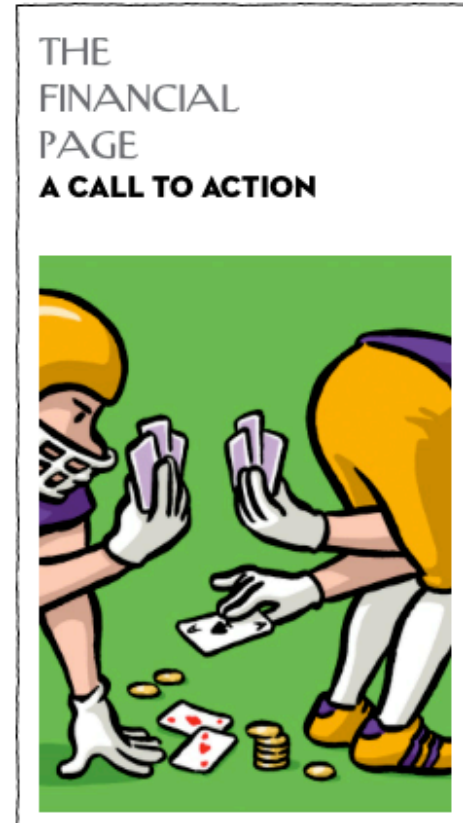

Illustration by Christoph Niemann.
T ast week, football fans across the country committed a crime: they bet on the Super Bowl. Billions of dollars was wagered on the game, almost all of it staked by people who live in states where sports gambling is against the law. Like participating in an N.C.A.A. office pool, betting on the Super Bowl is an all-American pastime. But in most of the country it's illegal.

New Jersey voters want to change that. In 2011, they overwhelmingly approved an amendment to the state constitution making sports betting legal, and early last year the state legislature passed a law to that effect. Dennis Drazin, the lawyer who advises the Monmouth Park racetrack, announced plans to set up a sports book. There's just one hitch: the federal government. In 1992, Congress passed a law banning sports betting everywhere in the U.S. except in the four states that already had some form of it (Nevada, Delaware, Oregon, and Montana). Now the four major professional sports leagues, the N.C.A.A., and the Justice Department are suing to prevent New Jersey from going ahead with its plans. Drazin told me that he'd like to be able to offer some kind of betting in time for March Madness. But that can happen only if the judge overturns the 1992 law as an unconstitutional infringement on states' rights.

The constitutionality of the federal ban on sports gambling may be an open question. But there's little doubt that permanently, and arbitrarily, dividing the country into "betting states" and "non-betting states" was terrible public policy. "It's completely irrational," I.

Nelson Rose, an expert on gambling law at Whittier Law School, says. "It's as if in 1929 Congress had decreed that a dozen states would be allowed to have sound in their movie theatres and all the other states would be able to show only silent films." That irrationality may reflect the country's deep ambivalence about gambling. Rose points out that, historically, the U.S. has oscillated between periods of permissiveness toward gambling and periods of crackdown. We're now in one of those permissive eras, which Rose calls "the Third Wave" of legal gambling. Betting has become ubiquitous, and a major source of revenue for states. Forty-three states and the District of

Exhibit 12, The New Yorker, Financial page, web 
Each researcher independently coded the content of the stories, highlighting facts and key statements, which enabled them to probe the participants' comprehension and retention of the information they read. This took the form of content questionnaires and narrative interviews in which the participants were assessed and measured both on their knowledge of what they had read and their strategies for reading in print and online.

The study employed the following procedures: documentation of qualitative observations on the behavior and activities at the research site; engagement in face to face qualitative interviews with the participants; focus groups that were unstructured with a few open-ended questions which are intended to draw out views and candid opinions from the participants; the use of public documents, newspapers and magazines, that have been independently coded by the three researchers on their content and a recording, audio and visual, to observe, document and archive the reading process.

The analysis of the study data was initially conducted to obtain a general sense of the information collected and to form an impression of its depth and credibility. This was followed by a detailed analysis of participant response to the coded questions to measure their understanding of the texts that were read. The researchers observed the time the participants took during reading, but this was not used as a measure of their reading ability. Diverse individual perspectives and quotations are included. Inter-coder agreement on the passages of texts ensured reliability and validity of the questions posed in relation to story content. The researchers triangulated the different sources of data to build a coherent qualitative set of measurements. Then working both in collaboration and independently they applied their unique theoretical perspective to an analysis of the texts. This input from three credible sources ensured triangulation throughout the study's analysis.

Creswell (2009) states that rich, thick descriptions are important in describing qualitative studies, as they provide an element of shared experiences. This method of reporting may also 
provide many perspectives about a study, which in turn provides results that are more realistic and richer. It also allows for discrepant information that runs contrary to the themes to be presented. Creswell also notes that by representing this evidence, the study becomes more realistic and valid.

\section{Recruitment of subjects}

University students from OCAD, Ryerson and York Universities were contacted by e-mail to participate in the study. They were given an overview of the study's purpose and the research processes involved in gathering the data. Print and online writers and editors were disqualified, as were information technology specialists who would bring a professional bias to the research study. Students with a visual impairment, for instance colour blindness, were also discouraged from responding.

Respondents who fit the study criteria were invited to a meeting with the research team. They were interviewed and screened with a questionnaire (Appendix 1) that probed their online and print information gathering methodologies. A combination of Internet and print reading was a prerequisite for a balanced study group and the screening questionnaire provided this. A consent form that in detail discussed the study, its video and sound recording and the interview process was provided. The three-hour duration of the study, a substantial time commitment, was discussed in detail with successful applicants. Eleven were chosen for the two study sessions.

\section{Expectations for the study}

The range of reading outcomes that have been measured by researchers to date fall into the following five types, speed, accuracy, comprehension, fatigue and the reader's preference for a print or electronic reading experience.

Speed: By far the most common examination of speed is the measured difference between print and online reading and its effect on comprehension, which itself is difficult to accurately measure. 
As Dillon (2008) notes, any causal relationship between reading digital texts and reduced comprehension would negatively impact the technology. The study observed the participants while they read and tested for comprehension, understanding the texts and the subsequent retention of the information, in a natural setting. Testing by measuring speed of reading might to the participants, feel like a reading proficiency test and would adversely affect their concentration, which could produce inaccurate data. In other words, we decided not to measure speed.

Accuracy: Previous studies have used proofreading to find spelling errors, additional or missing spaces, transpositions or additional letters and missing or inappropriate capitals, introduced by the researchers to measure accuracy. As accuracy is dependent on comprehension it is difficult understand how this process of measurement would succeed. What remains to be explored is how a reader engages in context with information in print and on a computer screen. The study was designed to use texts, news stories, which are concisely written to inform the reader. The accuracy of this type of content can be measured by tests based on careful coding of the texts by qualified editors. Probing questions can then be asked that measure the accuracy of the reader's retention of the information.

Comprehension: As Van Dijk and Kintsch (1983) have observed, to measure comprehension requires many different sub-processes, which include knowledge integration, coherence, and parsing. Asking questions on story content the researchers concluded was the most logical method of assessment. The texts from the three publications were carefully chosen so that the questions did not only demand good fact recall skills. Interpretation of the content's meaning was also required.

Fatigue: The study sessions lasted approximately three hours and required each participant to read six news stories and complete six questionnaires. The consent form allowed a participant to request a break or leave the study if the process for any reason makes them uncomfortable. Information technology has traditionally brought with it fears of harmful or negative side effects 
for users who spend a lot of time in front of a screen. As Dillon (2008) observes, in the area of screen reading this has manifested itself in speculation of increased visual fatigue and/or eyestrain when reading from screens as opposed to paper. The research team in their observations, monitored the reading process and planned breaks in the sessions when deemed necessary. Preference: Each of the study participants read three print stories and three electronic from the publications' electronic editions. In the focus groups that followed the readings the participants were asked about their comfort level reading in both media and whether they had a preference for one over the other.

Controlled variables: Bolter (2008) discusses navigation in print, which is, to the modern reader, linear and familiar when compared with a computer screen. Online reading requires constant multi-tasking as the cursor moves over the text. This in turn prompts the reader for a response by clicking or scrolling. Navigation was not measured in the study; however, the researchers observed the participants and opened up the focus group discussion to this aspect of online reading. Apple computer's software operating system, font display technology and computer hardware were used for the study. This eliminated flicker and screen resolution issues and jagged 'staircasing' which causes pixilated type. Apple renders type with anti-aliasing technology. This uses shades of gray to create the illusion of curved edges, improves the quality of type on screen and allows for the use of typefaces similar to those on the printed page. There is a great deal of academic conjecture on typefaces and their size for optimal reading in print and on screen. The length of lines of type, in industry term, the set width and the space between the lines, leading, have also come under close scrutiny. Few studies have allowed for the measurement of print and online publications in their normal typographic settings. In some previous studies academic expropriation of typography and design conventions has produced conflicting results. Designers vary the choice of serif letterform depending on what situation a typeface will be used in. They understand that sanserif is not more legible than serif for continuous text reading as many research studies have wrongly presumed. This has resulted in inexact and flawed data and Dillon 
(2008) notes that current research on electronic text and its presentation is piecemeal and of little use to industry.

Type and legibility: Designing for print is complex, but when successfully executed it gives the reader a clear and precise path to follow. The continuous evolution of printing has provided a vast array of typographic options that allow the print message to be coded, transmitted and subsequently decoded. There is no place for guesswork as to what typeface is most appropriate to test the reading process in print or online, for instance when researchers decide that Times New Roman is a suitable typeface to research online reading simply because it is the default serif on most computer systems, or for that matter that the ubiquitous Helvetica, designed in 1956, should be considered as the sanserif typeface of choice for online reading. There have been various attempts to create original typefaces designed for web use. Verdana is now used as an alternative to the default computer sanserif Helvetica and Georgia, a serif to replace Times New Roman. Both were designed by the renowned typographer Mathew Carter to replace the aging computer default newspaper typefaces. Verdana and Georgia, with their larger lower case letterforms, produce increased legibility in the same way that the correct typeface choice in the print world would (Lupton 2004).

What was not controlled: The print edition of The Guardian has a custom serif text font, Egyptian and uses both justified and flush left columns. Its website uses a sanserif typeface with a flush left setting of the text. The Economist uses a serif for print and a sanserif for online editions of its publication. The New Yorker has its own proprietary text font, a customized Adobe Caslon, for its print and iPad editions. The study respected the typographic conventions that the publications have adopted for their print and online editions by displaying the pages at the size the editors and designers intended. No online screen enlargements and original not photocopied printed pages were used in the study.

The study sessions: The study was conducted in a media lab at the Rogers Communications Centre at Ryerson University. The room had an open studio environment and a small lounge area 
ideal for quiet reflective reading. There were no outside distractions. To provide a consistent measurement process, MacIntosh computers and Apple's operating system and imaging technology were used. Two MacIntosh laptops and an iPad, each calibrated to balance the lighting environment of the room were the computer hardware. The print materials were the newsprint edition of The Guardian and the magazine quality gloss paper of The Economist and The New Yorker.

In each of the two study sessions the participants were divided into two groups. One read the print materials of the publications and the other the iPad edition of The New Yorker and the online editions of The Economist and The Guardian. Both groups were observed during the reading process by the research team and their actions were recorded on video. They were not timed as they read which allowed the participants to read as they would in a natural setting. After a short break of approximately ten minutes at the end of each reading, participants were asked to complete a questionnaire on story content. Then the print readers moved to the computers and the other group to print. The process was repeated, The New Yorker print reader moved to the iPad edition and The Economist and The Guardian print readers to their respective Internet publications. The computer readers moved to the print publications and subsequently read one article from each of the two remaining publications, in both print and electronic form. Each participant thus read one print and one electronic story from each publication for a total of six readings.

Story content: Texts were chosen from the three publications that were impartial and well written and of interest to a general audience. None had any local content or perspectives, which reduced the possibility of prior knowledge although The New Yorker piece on the working relationship between Obama and Clinton contained facts that were public knowledge. As Neuman, Just and Crigler (1992) have noted, each medium structures the information differently. The inverted pyramid style of newspaper writing that concentrates key aspects of a story early in the text was evident in The Guardian. Six of the key points were clustered in the first three paragraphs in a 
feature on the French painter Matisse. In a feature on a new US style gambling complex being built in Spain eight of the key points were contained in the first five paragraphs. In contrast, The Economist articles on a food scare in China and HIV in Africa had the key facts evenly distributed throughout the articles. The literary style of writing in The New Yorker wove the key facts evenly through the texts. They were also the longest stories that were measured.

The websites of The Economist and The Guardian published exactly the same story content as their print publications. The Guardian had two additional background paragraphs in the online gambling story that were not relevant to the key aspects of the story. Their web edition of the story on Matisse substituted a photograph of the artist for the print version's artwork. The New Yorker's iPad edition content was also identical to that of the print edition. It had additional material and videos of interviews with the writers. This was not included in the study. The content questions, a mixture of facts and numbers, were as follows:

The Economist; HIV and AIDS

1. What is one of the main problems in dealing with sexually transmitted diseases?

2. What related question do people tend to lie about?

3. At what University does the lead researcher, Steven Bellan, teach?

4. In how many African countries did he conduct his study?

5. What question about sexuality do people routinely lie about?

6. How many couples were surveyed?

7. What term was used to explain the early spread of AIDS in Africa?

8. In which scientific journal were the findings published?

The Economist; Yucky Kentucky

1. What three fast-food chains does Yum! Brands own?

2. What caused the health problem with the company's chicken in China?

3. By how much did Yum! Brands sales grow in 2012 ? 
4. By how much did sales fall in China in January?

5. How many stores did Yum Brands open in China last year?

6. What two items does Yum Brands offer on its menus to appeal to local tastes in China?

7. From what crisis did Yum Brands successfully recover?

8. How long do Yum Brand executives think it will take to recover from this scandal?

The Guardian; Euro Vegas

1. Which US company is this article about?

2. Which European city will be the site for a mega gambling complex?

3. How much is it expected to cost?

4. How big is the hotel in the development in terms of the number of rooms?

5. When is the facility due to open?

6. How many jobs are expected to be created by the project?

7. What do those opposed to gambling see as the negative social impact of the planned complex?

8. Sheldon Adelson, the man behind the project has similar complexes in two other locations. Where are they?

9. Which New York landmark will be replicated as part of the design?

10. Which hazardous health issue has to be resolved before the project opens?

The Guardian; Tate Makes the Cut

1. Which French artist's work is being featured at The Tate Modern?

2. When will the exhibit take place?

3. How many works of art will be on display?

4. Name one of the US galleries that will be contributing works to the show?

5. The artist began to compose works with colour cutouts, why? 
6. What famous painting did this process create?

7. When did the artist die?

8. The Tate will also stage exhibits featuring British art. Name one of the artists it will feature?

The New Yorker; A Call to Action

1. Which state voted to legalize betting in 2011 ?

2. In 1992 the US Congress Passed a law banning sports betting. Four states with sports betting in place were exempted. Who were they?

3. Which two states have no commercial gambling of any form?

4. How many states have lotteries?

5. According to major professional sports leagues, what will be the consequence of legalized sports betting?

6. Which sporting event does every office in America have a betting pool on?

7. How much do people in the US spend on sports betting a year?

8. Which other social issue are the individual states and US federal government wrangling over?

The New Yorker; Long Engagements

1. What position did Hillary Clinton hold in the US government?

2. How many years was she in that position?

3. What was the biggest foreign policy mishap of President Obama's first term?

4. Did Clinton support the 2009 surge in Afghanistan?

5. The author describes two massive historical initiatives that changed US foreign policy. What were they?

6. What one-word sums up Obama's approach to foreign policy? 
7. What are the two policy initiatives that the US is pursuing in its relationship with Iran?

8. What was that policy designed to do?

9. How many people does the article report to have died in the Syrian conflict?

10. Who did President Obama choose to replace Hillary Clinton? 


\section{Study results}

The first research question was, "Is the online reading process similar to reading the printed page as measured by the reader's comprehension and retention? If not why and how do they differ?" The conclusion from this study's results is that it is exactly the same in print and digital media. The participants demonstrated functional equivalency in both media. All eleven participants had a strong preference for print, which they read in depth. The second question, "What reading strategies that differ from print, do readers adopt when reading on-line" offered valuable insight into the online reading experience. When reading online the study group scrolls through the text to retrieve facts and then goes to print sources to verify the accuracy of the content. They do not engage with the content online as they do with print. The participant focus group reflections on the reading process online provided both comprehensive and consistent insights.

As Table 1 shows there was no measurable difference between the print and electronic reading processes. The participants were able to read and retain the key points across all of the media. Although comprehension was not measured independently of retention, issues arose when the group confused questions and answers by giving correct data in response to the wrong question. These comprehension miscues while few, were evident in both the print and electronic editions of the publications. As the focus group comments confirm, the approach to reading on the Web differs from that of print. On the Web, which is to the study group inaccurate and unstable, the preferred method is to scan, extract relevant facts and then seek other sources for confirmation. There is a profound apprehension around most Web content and its accuracy. But in the case of my study, the group considered the publications reliable and their content "fixed" and as such accurate. While some participants also scan print, they do so with the confidence that they can return to it to read in depth. The content will not disappear or be re-authored. It was viewed as stable by the study group, as one participant stated; "research is not an ideal reading situation online, the Internet creates a skimming mood. A browsing casual mode of article skimming of content to pick up the facts." The Web also presents so much content that the process of scrolling 
through it frustrates and annoys the reader. Heim (1997) notes that the more information that is accessed, the less significance is placed on it. This he concludes is a law of diminishing returns: "We get into the habit of clinging to knowledge bits and lose the feel of the wisdom behind knowledge (318)."

When the research is examined in depth it is apparent that despite this negative view of the Web in general, comprehension and retention in this case remains intact and is accurate. The participants' online coping strategy of scanning to retrieve facts then leaving is comparable in comprehension and retention to the more measured process of print reading. In the study they read both media in depth and returned to both to retain key facts. The functional equivalence findings in the study apply to the specific articles chosen, which were explicitly designed to be as much like the reliable print product as possible. The group successfully retained the core facts and numbers but the processing and retrieval of information they felt, differed. The printed page was to the study group a cultural object. As one participant noted, "You know what to expect opening a book or magazine, it is an understanding of content and process." Bishop (2005) states that scholars agree that print did not merely record but actually shaped culture, although discussion continues over the full implications of the print revolution. Eisenstein (1979) argues that large movements such as the Renaissance and the Reformation did not simply make use of the printing press but were in fact a function of the shift from a scribal to a print culture.

As noted above, the goal of the study was to measure the reading process in print and online. The content was carefully selected and was identical in both media, print and online. Of the three publications, The Economist's writing style, one that spreads the key points evenly throughout the article delivered a slightly more accurate retention of information in its digital edition than The Guardian's clustering of key points. As Neuman, Just and Crigler (1992) note, a newspaper's inverted pyramid writing tends to make it too dense and complex for some audiences. This was not reflected in this study as the participants scored well in all three publications. The New Yorker with its literary style requires the reader to focus closely on the content and the nuances of the 
writer's argument. Its articles were also the longest and its reading scores were lower. Some of the participants felt that the iPad had some of the tactile aspects reminiscent of a printed book, in particular its size and look and feel and gave a clear reading experience compared to the Web.

They had no problems with the story content from the three publications and were engaged in the process of reading. As noted above they had a strong preference for the print editions in the study and in particular the newspaper's full-page presentation. Despite the fact that the online stories were compact and the same length as the print, psychologically scrolling on the Web makes them impatient. With print they had a starting point and a finishing point in full view.

The rates of comprehension and retention of information were as follows:

$\begin{array}{lcc}\text { The Economist: Comprehension and retention } & \text { Print 68.75\% } & \text { Digital 70.9\% } \\ \text { The Guardian: Comprehension and retention } & \text { Print 69.5\% } & \text { Digital 68.75\% } \\ \text { The New Yorker: Comprehension and retention } & \text { Print 61.75\% } & \text { Digital 63.25\% }\end{array}$

Table 1

Comparison of print and on screen readers:

A one way between groups ANNOVA test of homogeneity of variances

$\begin{array}{llllll}\text { Score } & \text { Sum of squares } & \text { Df } & \text { Mean squares } & \text { F } & \text { Sig } \\ \text { Between groups } & 1.475 & 1 & 1.475 & .005 & .942\end{array}$

$\begin{array}{llll}\text { Within groups } & 15247.220 & 56 & 272.272\end{array}$

Total $\quad 1548.695 \quad 57$

As the ANNOVA test shows, there was no statistical difference between the two reading groups.

The reading groups demonstrated functional equivalency for retention in print and online reading. 


\section{Focus groups}

At the completion of the reading portion of the study, an informal interview and focus group discussion was conducted. The participants were again briefed on the importance of the research project and asked to discuss the presentation of new stories in the three media, print, iPad tablet, and computer. After the group had openly discussed the issues that a potentially disruptive new technology brings to the reading process they were asked questions based on the researchers' observations. "Has this experience changed your opinion about technology" or "Is there anything missing for you" or "Do you have any suggestions for further research?"

As Flick (2007) notes, focus groups as an additional methodological step allows the participants to evaluate, comment on and criticize aspects of the study. This produces additional results at a different level, group interaction instead of single interviews. In the two focus groups, participants were very articulate in their descriptions on the approach to reading in print and online. They understood that the study had used material from what they considered trusted news and opinion sources. Their approach to the general discussion of reading online was conditioned by their previous experience. It was not a reflection of their reading experience during the study.

\section{Dan B.}

"More and more I am feeling like the Internet (in general) is a hindrance to communication rather than a benefit to it because people are becoming encased in their own flows of information that validate their pre-existing ideas and do not challenge them with new info."

"I always save PDF versions of interesting web articles because I am generally afraid of not being able to retrieve them again as a bookmark. Also, the ads always change, and sometimes this is an interesting component that I want to preserve."

"I can usually tell with ease how long an article is on a browser, simply by examining the size of the scroll bar, and scrolling a little bit through the article. This is comparable to 
when I read print --- I look at the headline, then the picture, then the caption for the picture, then any other larger text captions, and finally the body text of the article."

\section{Vivian L.}

"I use the Internet for research but prefer to read print if possible... Scanning the articles (on the Internet) to pick out relevant facts then leave: I read multiple sources online for confirmation, then look for the print equivalent." She also scans print repeatedly "To assess the quality of the information but I return to the printed page to read."

"I read novels in print for pleasure reading, crime mysteries and science fiction when I have the time." As a student she has no access to TV but picks up headline news from CNN, BBC and Twitter. Then accesses the material online if it looks interesting. Vivian thinks that the iPad mimics print and likes the option of scrolling without ads, although the ads are placed, as they would be in print, which is less intrusive than the Internet. "The iPad gives a clear reading experience as opposed to the Web which with the advertising clutter distracts me. Psychologically, scrolling on the Web makes me impatient and it feels that it takes forever. In print you know when it starts and finishes, unlike the Web, which is endless."

"I rarely revisit a site but the value of print is books and magazines are always accessible. Skimming onscreen is for sure not easy on the eye with light shining into the eyes. I retrace skimming several times to get the meaning online. I retain a lot more in print." She notes that newspapers print apologies for their errors, "Web apologies when given, are corrected via Twitter.”

She agrees that print is more trusted. "I grew up with print but younger people do not have the benefit of print." 


\section{Brendan G.}

"You know what to expect unlocking quality information. You can read a book and then sum up its content in a few sentences. Online I skim the screen to get facts. I am impatient reading longer online material. One paragraph is the most I would read." "The Internet is no place to digest information, it is no place to absorb long articles. The Internet is instantaneous, but a ton of text is an impediment. Print contains more important information, someone has made decisions, and it is more official, more quality words."

"Books look more planned, are more tactile. Not like the Internet, books are crafted (but) online is ubiquitous. Online is anarchy, everyone is free to publish."

\section{Kim E.}

"I research for art text and images online but prefer print. Images translate better in print, I source the Internet then go to print."

"I pick up news first on Facebook then goes to the BBC online to verify. I trust them and online is updated more frequently."

"I read novels and classic literature for leisure reading, when I can find the time." "Print reading is slower than online and retention is better, grammatical errors online reduce the content's meaning."

\section{Sasha O.}

"For pleasure print magazines and novels are more at hand, tactile. Single page reading in newspapers is similar to the iPad. It is organized. The New Yorker online when scrolling down and reading you can keep track better."

She skims more in print because she can go back to it. "Online might not be there next time, print skimming is more efficient. Print format is easier to read, I always print out 
PDF's to read. It is better working with print."

Nathan N.

"I skim two or three times to get information online. I search blogs then print out PDF's to read and annotate."

“Online content can be re-authored" (Without the reader's knowledge).

\section{Sara A.}

"The web is not tactile, print feels permanent, you can take it anywhere."

She does not read e-books only print. "It has no reflection. You can remember print locations and how far to go" (To the end of the article).

"You can underline, dog-ear print." She reads blogs and finds them engaging, and they have extra added on content messages. "I cannot take Twitter seriously."

“Online, tabs are everywhere and you are multi-tasking, print reading is simpler, more focused."

\section{Chibi K.}

"I fact check in print editorial content found online, Web first quickly, then print to double check the facts." She is most comfortable with a book, not technology with its downside, which hurts the eyes working the tabs. "I read blogs for entertainment but could write them better, it's fluff and image based." She values print and saves articles to share with others. "Online is just reading texts, no planning, the Internet is out of control."

Reg B.

He has news feeds from various sites, which create his personal news service. 
“I cannot give up books, my physical memory tracks spreads in print." He has a Kobo, a tablet and smart phone but "Reading is claustrophobic online." He feels that newspaper presentation allows him to plan when to read. "I have time to read that now."

"Compared to a well-designed print book, online is crap, cluttered layouts not gentle on the eyes with the grayed out screen. Type in a book looks balanced, HTML looks like default and reformatting creates mayhem.”

During both focus group sessions the participants described the reading process both print and online in general, in strong and articulate language. There was no hesitation, no ambiguity and as a group they spoke with a single voice. As Neuman (2006) notes, qualitative researchers do not treat a document as simply a container, rather they examine the context and emphasize the entire process from its creation to consumption: "In short they treat the document or report itself as a cultural object that carries social meaning in its own right (323)." He concludes that qualitative researchers emphasize that people think and interact based on meaning, not simply with words and numbers. The data from the study, although a small sampling, indicates that the reader, who has a history reading print, has devised strategies for searching for and retrieving information from the Web. With these interpretive strategies, protocols developed through print, a new active reader is emerging. It is not reading in the conventional sense of reviewing then engaging with an author's writing as in print to extract meaning. Rather it is a process of scanning a text to extract facts.

Although the content of both media was identical, the participants preferred the print reading experience with all three publications. As one stated, "Print vs. online may be similar content, but print is preferred because online is not an easy reading process." Print however was not their primary source of news. The Internet with its immediacy was the overwhelming choice for checking on breaking news. While they followed national and world news, their interest ranged from daily reading to once or twice a week. Twitter, Facebook and email prompts from friends 
were often the stimulus to begin a news search. World news, politics, sports and entertainment were the most popular topics. If a news item of international importance required verification, the group overwhelmingly chose television as the medium: $\mathrm{BBC}$ television and online news, $\mathrm{CNN}$, $\mathrm{CBC}$ then Internet news sources. While all of the participants read print for pleasure they would go to a print source for background information or to double check facts to confirm the accuracy of the other media. The literature that they read for pleasure was wide ranging: from the classics to current works on civilization, politics and the impact of new technologies.

The content of The Guardian, The Economist and The New Yorker interested the group but the women in the study were less interested in The New Yorker column on sports betting. Although they stated that interest in a subject allows for better retention, it did not prevent them from reading and understanding the complexities of sports betting. The Economist articles were brief and on a page with other content. The New Yorker story on the relationship between Clinton and Obama required multiple page turns. The Guardian print edition was singled out as a very functional medium. Its presentation allows the reader to plan how and what to read on the page by gauging the time commitment required. One participant put it this way: "Print readers read closer than online, more interaction with the page, especially the newspaper."

The broadsheet full page or in the study The Guardian with its Berliner super-tabloid format, gives the reader a full view of the content. To one participant, that made it feel more complete, more official. If someone has gone to the trouble and cost of organizing the content of the page, the information must be correct, he concluded. Another comment on the single page discussed the iPad's 'single long view' as having the best features of print and computer. Members of the group also concluded that scrolling without intrusive advertisements allows for better concentration and a cleaner reading experience.

Nord (2001) explores the strategies that readers used to make sense of what they read. He notes that rather than being a transmission of the meaning of a newspaper's text to a reader, reading is in fact a transaction between the text and the reader. In attempting to make sense of the 
information, the reader sees the text through the lenses of interpretive strategies. It involves the codes and canons of culture.

\section{Discussion}

McLuhan's (1964) statement that when a message passes through a new medium, the medium alters the message predated the Internet but is still valid. To the study group the Web is not an environment where information can be trusted. The content becomes fluid. When a message is fluid it is unstable and remains so. In this constant shifting state, information can be altered, deleted, parsed, or through the actions of a search engine or database, substituted.

As Heim (1997) notes, because digital texts are not confined to pages as print is, they stretch out and can link to other data. In this way all digital texts create universal hypertexts: "Digital text is thus quintessentially postmodern in destabilizing and making text flexible (317)." Chartier (1995) notes that electronic textuality alters not only the author's message but how a reader might accept or reject it: "It enables an open, fragmented, and relational articulation of reasoning made possible by hypertextual links (4)." The open nature of the Web as medium means that the websites are rarely finalized, "fixed," because a website's content is constantly being updated. It is not possible to trust content if it keeps changing. However, the linear individualistic mentality learned through print gave the study group participants the skills to successfully navigate through the dense web of information that constitutes the Internet.

In print the reader decodes what she sees on the page allowing her to quickly absorb and parse large amounts of text, discarding redundant content. The question now becomes, which print reading operations are being transferred to the process of scanning online texts to extract relevant facts? The study participants voiced concern over the amount of text that has to be processed when conducting research on the Web. As one participant in this study stated: "Reading is claustrophobic online." He preferred the newspaper presentation that allows him to plan when to 
read by giving him an orderly presentation of content. Story presentation and hierarchy, key elements of the print design process are less evident or absent online. As a consequence, as previous research demonstrates, online readers are more poorly informed than print readers -- but not in this case. The research from this study demonstrates that when the authors of the print media in The Guardian, The Economist and The New Yorker, are those who also control the integrity of online content, the print and web readers are equally informed.

Dillon (2008) notes that the concept of a schema for electronic documents lacks the history of print and to date, schematic structures for information on paper have little or no electronic equivalents. However, the study's findings and focus group interviews suggests that schemata structures for processing information would now appear to be used extensively when a reader engages with an electronic text. For example in the reading portion of the study the participants were measured on the reading process in print and online. All were well versed in both media and the researchers did not observe any problems or obvious discomfort with either. Comprehension of the text and retention of information, some of which required interpretation, was extracted correctly from both media. Only one out of fifty-two questions was incorrectly answered by all of the participants. There was a preference for print because it was felt that the printed page was a reliable source of information. Despite the fact that the Web was unreliable, inaccurate, difficult to navigate, awkward to read because of screen glare and too cluttered, the study group achieved functional equivalency in both media. But this was only achieved with the carefully curated content identical online to the trusted print version. The rest of the Web is still out of control and cannot be trusted. Members of the study group have learned that the online experience is more complex and requires more time and effort.

The study was designed to observe print and computer based reading and to measure and compare rates of comprehension and retention. The discovery that the participants had such a strong aversion to the Web and that they did not trust its content (unless as in this case, they had a credible source) surprised the research team. If the findings of this study are confirmed in 
subsequent research studies on the process of reading online it will have profound implications for industry. Advertising to be successful requires the reader to engage with and respond to a message. There is strong evidence that this is not the case with what the advertising industry would consider an important core audience.

Since the time of Aldus Manutius, printing has required attention to typographic detail. How a reader approaches a text and what typographic cues are needed to successfully engage in the reading process with that text. Typography provides language with visual form and through that form conveys the meaning of a text. When a text is transferred to the Web, HTML software protocols delete these subtle but important aspects of print and the result is confusion and a loss of meaning unless the HTML coding is typographically enhanced. The group had serious problems with HTML texts, which contributed to their frustration with online research and reading. The study publications' Web editions successfully transferred print typographic cues and the resulting structure allowed the texts to be measured functionally equivalent to print. The study results would appear to support this approach to website design although further research will be required to measure the gap between enhanced typographic and HTML texts.

Some forms of online writing style were to the participants unsuited for reading and research and were a hindrance to communication rather than a benefit to it: "People are becoming encased in their own flows of information that validate their pre-existing ideas and do not challenge them with new information.” The editorial content studied came from highly regarded English language publications and was published in its full form in both the print and online editions. Stories that are optimized for print are well suited for online publication; they are well researched and edited, as close to being factually correct as breaking news allows and are concise. A comparative study between this news and general Web content would confirm if this is indeed the case. It would also shed light on the value of open-ended Web publishing where space permits a vast amount of material to be accessed.

An understanding of the complexities of online reading outcomes and comprehension and 
engaging with alternative texts that respond differently than print has yet to be successfully investigated -- for example, texts that inform in new and unpredictable ways. This is beyond the scope of this study. Corio (2011) and RAND (2002) have investigated this new phenomenon and have only posed the suggestion that it is different and needs to be investigated. They give no pointers and no roadmap. If the Web is the future, which it appears it is, we are in a post Gutenberg landscape without a real sense of direction. The study participants have constructed coping strategies based on print protocols as a stopgap measure. As the history of print has shown us, new conventions and protocols have a tendency to surface during the evolution of a new technology. We just have to choose the correct ones. 


\section{Appendices}

\section{Appendix 1}

\section{STUdY OF PRINT AND COMPUTER BASED READING, RYERSON UNIVERSITY}

Have you ever been employed in journalism?

Have you been diagnosed as coggnatively impaired?
Have you any known vision imparement?

Have you been diagnosed with a learning disorder?

What is your primary source of news. Please check one

Internet Twitter Television Newspaper Magazine Radio

How often do you follow national or international news

Every hour Twice a day Daily
Once or twice a When a major Never week story breaks

Have you ever contributed to one of the following news sources

Twitter Internet blog Newspaper News website On-Line forum Other

What type of news interests you most.

World news Politics Sports Entertainment Celebrity gossip Other

What Was the most memorable book or piece of literature that you have read? Please state why

What is your level of education.

\begin{tabular}{|c|c|c|c|c|}
\hline $\begin{array}{l}\text { High school } \\
\text { diploma }\end{array}$ & $\begin{array}{l}\text { Undergraduate } \\
\text { degree }\end{array}$ & Masters degree & $\mathrm{Phl}$ & Other, please state \\
\hline
\end{tabular}

If an attempt was made to assassinate the President of the United States, where would you check for confirmation of the news? 


\section{Notes}

\section{Saccadic eye movements}

It has been known for over 100 years that when we read, our eyes don't move smoothly across the page, but rather make discrete jumps from word to word. We fixate on a word for a period of time, roughly $200-250 \mathrm{~ms}$, then make a ballistic movement to another word. These movements are called saccades and usually take 20-35ms. Most saccades are forward movements from 7 to 9 letters, but $10-15 \%$ of all saccades are regressive or backwards movements. Most readers are completely unaware of the frequency of regressive saccades while reading. The location of the fixation is not random. Fixations never occur between words, and usually occur just to the left of the middle of a word. Not all words are fixated; short words and particularly function words are frequently skipped. During a single fixation, there is a limit to the amount of information that can be recognized. The fovea, which is the clear center point of our vision, can only see three to four letters to the left and right of fixation at normal reading distances. Visual acuity decreases quickly in the parafovea, which extends out as far as 15 to 20 letters to the left and right of the fixation point.

Eye movement studies indicate that there are three zones of visual identification. Readers collect information from all three zones during the span of a fixation. Closest to the fixation point is where word recognition takes place. This zone is usually large enough to capture the word being fixated, and often includes smaller function words directly to the right of the fixated word. The next zone extends a few letters past the word recognition zone, and readers gather preliminary information about the next letters in this zone. The final zone extends out to 15 letters past the fixation point. Information gathered out this far is used to identify the length of upcoming words and to identify the best location for the next fixation point.

Kevin Larson, Advanced Reading Technology, Microsoft Corporation, July 2004. 
2. Apple Computer screen rendering technology

Anti-aliasing type on a computer screen enhances the quality of the typeface by adding grey pixels to a round area of a letterform. This gives the illusion of a smooth crisp letter and prevents pixelization where a ragged, disruptive letterform is created by attempting to create a round shape with square pixels. Computer software operating systems display colour and render type on screen using proprietary technologies. Microsoft Windows displays text by using Truetype, a font rendering technology they developed. Apple's display technology works with Postscript, a technology developed by Adobe Systems that has become the standard for display and imaging of the printed page. Publishing industry experts view it as a superior technology to that of Microsoft. This has resulted in the adoption of the Macintosh computer as the defacto hardware for the publishing industry. 


\section{Sources}

Bishop, E. L. 2005. "Book History.” In The Johns Hopkins Guide to Literary Theory and Criticism. Johns Hopkins University Press.

Bolter, J., B. 2003. Seeing and Writing: The New Media Reader. MIT Press, Cambridge, MA.

Bringhurst, R. 2005. The Elements of Typographic Style. Hartley and Marks, Publishers, Vancouver, Canada. De Brujin (1992)

Chartier, R. 2011. "History, Time and Space." In Journal for the Study of knowledge, Politics and the Arts. Stanford University Press.

Connell, C., L. Bayliss, W. Farmer. 2012. Effects of eBook Readers and Tablet Computers on Reading Comprehension, Virginia Tech University.

Corio, J. 2011. "Predicting Reading Comprehension on the Internet: Contributions of offline Reading Skills, Online Reading Skills, and Prior Knowledge." In Journal of Literacy Research, 2011.

Corio, J. 2003. "Reading Comprehension on the Internet: Expanding our Understanding of Reading Comprehension to Encompass New Literacies." In The Reading Teacher, 2003.

Creswell, J. W. 2009. Research Design: Qualitative, Quantitative and Mixed Methods Approaches. Sage, Los Angeles, London.

d'Haenens, L., N. Jankowski, A., Heuvelman. 2004. "News in Online Newspapers: Differences in Reader Consumption and Recall." In New Media and Society.

Dillon, A.2008. Designing Usable Electronic Text. Taylor and Francis, London, UK.

Eisenstein, E. 1979. The Printing Press as an Agent of Change. Cambridge University Press, UK.

Flick, U. 2007. Managing Quality in Qualitative Research. Sage Publications, London, Thousand Oaks.

Gane, N. 2005. "Radical Post-humanism: Friedrich Kittler and the Primacy of Technology." In Theory, Culture and Society, Sage, London, Thousand Oaks.

Goldstein, P. 2005. "Reader Response Theory and Criticism.” In The Johns Hopkins Guide to Literary Theory and Criticism. Johns Hopkins University Press.

Graber, D. A 1998. Processing the News: How People Tame the Information Tide. University of Illinois at Chicago.

Hansen, M. B. N. 2009. Media Theory, Theory, Culture and Society. SAGE, London, Thousand Oaks.

Hatt, F. 1976. The Reading Process. London, Clive Bingley. 
Heidegger, M. 1983. Hebel, Friend of the House, trans., Foltz, B., and M. H. Heim. Pennsylvania State University Press.

Hesse, C.1996. The future of the Book. University of California Press, Berkley, Los Angeles.

Heim, M. H. 1997. Heidegger, McLuhan and the Essence of Virtual Reality. Oxford University Press, Oxford.

Heim, M. 1997. The Computer as Component. Oxford University Press, Oxford, UK.

Hollander, B. A., D. M. Krugman, T. Reichert, J. A. Avant. 2011. The E-Reader as Replacement for the Print Newspaper. Springer Business Media LLC.

Innis, H. 1951. The Bias of Communication. The University of Toronto Press, Toronto.

Johns A. 1998. The Nature of the Book. University of Chicago Press, Chicago, London.

Keep, C. 2005. "Hypertext Theory and Criticism." In The Johns Hopkins Guide to Literary Theory and Criticism. Johns Hopkins University Press.

Lewenstein, M., G. Edwards, D. Tatar, A. DeVigal. 2008. Stanford University, Poynter Online Eye-Track Study. Stanford University, Poynter Institute for Media Studies, USA.

Lupton, E. 2010. Thinking With Type: A Critical Guide for Designers, Writers, Editors \& Students. Princeton Architectural Press, New York.

Manovitch, L. 2012. Software Culture. MIT Press, Cambridge MA.

Marchionini, G. 2010. Information Concepts: from Books to Cyberspace Identities. Morgan and Claypool Publishers.

Marshall, C., C. 2010 Reading and Writing the Electronic Book. Morgan and Claypool, San Rafael CA, USA.

Marshall, C., C. 2007. The Grey Lad Gets a New Dress: A Field Study of the Times News Reader. Microsoft Corporation, Redmond WA, USA.

Martin, D. 2011. Interview conducted at, Seneca College of Applied Arts \& Technology, Toronto

McLuhan, M. 1964. Understanding Media: The Extensions of Man. The University of Toronto Press, Toronto.

Neuman, W. L. 2006. Social research Methods: Qualitative and Quantitative Approaches. Pearson Education, Boston MA, 2006.

Neuman, W.R., R. J. Marion, A. N. Crigler. 1992. Common Knowledge; News and the Construction of Political Meaning. The University of Chicago Press, Chicago and London.

Nielson, J., K. Pernice. 2010. Eye-tracking Web Usability. Pearson Education. 
Nord, D.P. 2001. Communities of Journalism. University of Illinois Press, Chicago.

Nossek, H., H. Adoni. 2006. The Future of the Book in the Digital Age. Chandos Publishing, Oxford, UK.

Pettegree, A. 2010. The Book in the Renaissance. Yale University Press, New Haven, London.

The RAND Reading Study Group. 2002. Reading for Understanding. The RAND Corporation,, Arlington, VA.

Shannon, C., W. Weaver. 1949. The Mathematical Theory of Communication. University of Illinois Press.

Sher, R.B. 2006. The Enlightenment and the Book. University of Chicago Press, Chicago, London.

Tewksbury, D., S. L. Althaus. 2000. "Differences in Knowledge Acquisition among Readers of the Paper and Online Versions of a National Newspaper." In J \& MC Quarterly, Vol. 77 No. 3 .

van Dijk, T. A., W. Kintsch 1983. Strategies of Discourse Comprehension. London, Academic Press.

Watters, C.R., M. A. Shepherd, T. Chiasson, L. Manchester. 2004. Digital Documents: Systems and Principles. Springer-Verlag, Berlin, Heidelberg, New York.

Zambarbieri, D., E. Carniglia. 2012. "Eye Movement: Analysis of Reading from Computer Displays, eReaders and Printed Books." In The Journal of the College of Optometrists. 